\title{
The effects of growth rate and biomechanical loading on bone laminarity within the emu skeleton
}

\author{
Amanda L Kuehn ${ }^{1}$, Andrew H Lee ${ }^{2}$, Russell P Main ${ }^{3}$, Erin LR Simons ${ }^{\text {Corresp. } 4}$ \\ ${ }^{1}$ Arizona College of Osteopathic Medicine, Midwestern University, Glendale, AZ, United States \\ 2 Department of Anatomy, College of Graduate Studies, Arizona College of Osteopathic Medicine, College of Veterinary Medicine, Midwestern University, \\ Glendale, AZ, United States \\ 3 College of Veterinary Medicine, Purdue University, West Lafayette, IN, United States \\ 4 Department of Anatomy, College of Graduate Studies, Arizona College of Osteopathic Medicine, Midwestern University, Glendale, AZ, United States \\ Corresponding Author: Erin LR Simons \\ Email address: esimon@midwestern.edu
}

The orientation of vascular canals in primary bone may reflect differences in growth rate and/or adaptation to biomechanical loads. Previous studies link specific canal orientations to bone growth rates, but results between different taxa are contradictory. Circumferential vascular canals (forming laminar bone) have been hypothesized to reflect either (or both) rapid growth rate or locomotion-induced torsional loading. Previous work on the hindlimb biomechanics in the emu shows that the femur and tibiotarsus experience large shear strains, likely resulting from torsional loads that increase through ontogeny. Here, we test how growth rate and biomechanical loading affect bone laminarity in wing and hindlimb elements from growing emu ( 2 - 60 wks). If laminar bone is an adaptation to torsioninduced shear strains, it should increase from juveniles to adults. Alternatively, if bone laminarity reflects rapid growth, as has been shown previously in emu, it should be abundant in fast-growing juveniles and decrease with age. Transverse mid-shaft histological sections from the limb bones (femur, tibiotarsus, humerus, ulna, and radius) were prepared and imaged. Growth rates were measured using fluorescent bone labels. Vascular canal orientation was quantified using laminarity index (proportion of circumferential canals). Principal components analysis was performed to convert highly correlated variables (i.e., mass, age, growth rate, and shear strain) into principal components. Random-intercept beta regression modeling determined which principal components best explained laminarity. The fastest growth rates were found in young individuals for all five skeletal elements. Maximum growth rate did not coincide with peak laminarity. Instead, in the femur and tibiotarsus, elevated laminarity is strongly correlated with adult features such as large size, old age, and modest growth rate. This result is contrary to predictions made based on a previous study of emu but is consistent with results observed in some other avian species (penguin, chicken). Shear strain in the caudal Peer] reviewing PDF | (2018:05:27991:3:1:NEW 29 Jul 2019) 
octant of the femur and tibiotarsus is positively correlated with laminarity but has a weaker effect on laminarity relative to mass, age, and growth rate. Laminarity in the wing elements is variable and does not correlate with ontogenetic factors (including mass, age, and growth rate). Its presence may relate to relaxed developmental canalization or a retained ancestral feature. In conclusion, ontogeny (including growth rate) is the dominant influence on vascular canal orientation at least in the hindlimb of the emu. 
1 The effects of growth rate and biomechanical loading on bone laminarity within the emu

2 skeleton

3

4 Amanda L. Kuehn' ${ }^{1}$, Andrew H. Lee ${ }^{2}$, Russell P. Main ${ }^{3}$, Erin L. R. Simons ${ }^{4}$

5

$6 \quad{ }^{1}$ Arizona College of Osteopathic Medicine, Midwestern University, Glendale, AZ, USA

$7 \quad{ }^{2}$ Department of Anatomy, College of Graduate Studies, Arizona College of Osteopathic

8 Medicine, College of Veterinary Medicine, Midwestern University, Glendale, AZ, USA

$9{ }^{3}$ College of Veterinary Medicine, Purdue University, West Lafayette, IN, USA

$10{ }^{4}$ Department of Anatomy, College of Graduate Studies, Arizona College of Osteopathic

11 Medicine, Midwestern University, Glendale, AZ, USA

14 Corresponding Author:

15 Erin Simons ${ }^{1}$

16

17 Email address: esimon@midwestern.edu

18

19

20

21

22

23 


\section{ABSTRACT}

The orientation of vascular canals in primary bone may reflect differences in growth rate

and/or adaptation to biomechanical loads. Previous studies link specific canal orientations to bone growth rates, but results between different taxa are contradictory. Circumferential vascular canals (forming laminar bone) have been hypothesized to reflect either (or both) rapid growth rate or locomotion-induced torsional loading. Previous work on the hindlimb biomechanics in the emu shows that the femur and tibiotarsus experience large shear strains, likely resulting from torsional loads that increase through ontogeny. Here, we test how growth rate and biomechanical loading affect bone laminarity in wing and hindlimb elements from growing emu (2 - $60 \mathrm{wks})$. If laminar bone is an adaptation to torsion-induced shear strains, it should increase from juveniles to adults. Alternatively, if bone laminarity reflects rapid growth, as has been shown previously in emu, it should be abundant in fast-growing juveniles and decrease with age. Transverse midshaft histological sections from the limb bones (femur, tibiotarsus, humerus, ulna, and radius) were prepared and imaged. Growth rates were measured using fluorescent bone labels. Vascular canal orientation was quantified using laminarity index (proportion of circumferential canals).

Principal components analysis was performed to convert highly correlated variables (i.e., mass, age, growth rate, and shear strain) into principal components. Random-intercept beta regression modeling determined which principal components best explained laminarity. The fastest growth rates were found in young individuals for all five skeletal elements. Maximum growth rate did not coincide with peak laminarity. Instead, in the femur and tibiotarsus, elevated laminarity is strongly correlated with adult features such as large size, old age, and modest growth rate. This result is contrary to predictions made based on a previous study of emu but is consistent with results observed in some other avian species (penguin, chicken). Shear strain in the caudal octant 
47 of the femur and tibiotarsus is positively correlated with laminarity but has a weaker effect on

48 laminarity relative to mass, age, and growth rate. Laminarity in the wing elements is variable and

49 does not correlate with ontogenetic factors (including mass, age, and growth rate). Its presence

50 may relate to relaxed developmental canalization or a retained ancestral feature. In conclusion,

51 ontogeny (including growth rate) is the dominant influence on vascular canal orientation at least

52 in the hindlimb of the emu.

53

\section{INTRODUCTION}

Avian bone tissue is highly vascularized with a fibrolamellar structure, which allows for rapid growth by depositing randomly arranged spicules of woven bone initially, followed by in-

57

filling of the cancellous spaces with centripetal lamellar bone, forming primary osteons (Francillon-Vieillot et al., 1990; de Ricqlès et al., 1991; Curry, 2002). Each primary osteon contains a central canal that houses blood vessels and nerves. These vascular canals vary in orientation and bones can be classified based on the predominant canal orientation. Laminar bone typically has a higher proportion of canals with circumferential orientation (parallel to the periosteal surface of the bone) relative to other orientations. Additional canal orientations include: radial, those orthogonal to the periosteal surface; longitudinal, those running parallel to the long axis of the bone; and oblique, all other orientations (de Ricqlès et al., 1991).

It has been hypothesized that differences in primary vascular canal orientation might be a reflection of growth rate, biomechanical loads, or phylogenetic relationships (Padian, 2013). Amprino (1947) first suggested that the organization of bone microstructure may be influenced by bone growth rate, such that woven bone is deposited during rapid growth and lamellar bone during slow growth (de Ricqlès et al., 1991). Further studies have investigated whether specific 
70 primary vascular canal orientations in fibrolamellar bone are also associated with slow or fast

71 growth by directly comparing microstructure with bone growth rates measured through the use

72 of injectable fluorochromes (Castanet et al., 2000; de Margerie et al., 2002; de Margerie et al.,

73 2004). Rapidly growing hindlimb bones of ratites have been found to exhibit structure that is

74 laminar and reticular (bone with numerous obliquely-oriented canals), whereas the more modest-

75 growing wing elements of ratites exhibit reticular and longitudinal canal structure (Castanet et

76 al., 2000). This suggests that laminar bone, in part, may reflect faster growth rates. This result

77 was supported in a recent study of pigeon wing elements, which showed that peak laminarity

78 (proportion of laminar bone) coincides roughly with the growth spurt in each element (Ourfalian,

79 Ezell \& Lee, 2016). However, work on mallard long bones showed no relationship between

80 growth rate and predominant vascular canal orientation (de Margerie et al., 2002). Additionally,

81 in the king penguin, radially-oriented canals dominated in the fastest growing sections, not

82 circumferential canals (laminar bone) (de Margerie et al., 2004). Likewise, chickens selected for

83 fast growth showed limb bones with predominantly radial canals (Williams et al., 2004; Pratt and

84 Cooper, 2018).

85 Laminar bone has been hypothesized to better resist torsional loading. In laminar bone,

86 the bone tissue is arranged in 'sheets' or 'plates' between layers of circumferential canals. Shear

87 strain is thought to flow continuously within these 'sheets', and thus the concentrated stresses on

88 the bone tissue surrounding the canals is reduced (de Margerie et al., 2004). Indeed, bone

89 elements that are hypothesized to predominantly experience torsional loads have been found to

90 exhibit laminar bone. Laminar bone is found to be most abundant in the humerus, ulna, and

91 femur in a large sample of flighted bird species (de Margerie, 2002; de Margerie et al., 2005). In

92 vivo strain gauge studies have shown that these elements experience predominantly torsional 
93 loads in at least some species: the humerus in the pigeon during flapping flight, the ulna in the

94 turkey during wing flapping while on the ground, and the femur in the chicken and emu during 95 terrestrial running, (Rubin and Lanyon, 1985; Biewener and Dial, 1995; Carrano and Biewener, 96 1999; Main and Biewener, 2007).

97 A limitation of previous studies of laminar bone is the indirect comparison of bone

98 histology in one species with bone growth rates and/or in vivo strain gauge measures taken from

99 different species. In this study, we present an analysis of laminar bone in a species in which bone 100 growth rate and in vivo bone strain data were directly measured. The emu (Dromaius

101 novaehollandiae, Order Struthioniformes, Family Dromaiidae) is a flightless bird endemic to

102 Australia, but widely farmed in the US. The individuals included in this study comprise a growth 103 series that were previously injected with fluorescent bone labels and surgically implanted with 104 gauges to measure in vivo locomotor strains in the femur and tibiotarsus (Main and Biewener, 105 2007). Shear strains, produced by torsional loads about the long axes of the bones, were the 106 predominant type of strain in the two bones and increased from juveniles to adults (Main and 107 Biewener, 2007). Bone strains were not measured in the wing elements of these individuals. 108 Presumably, shear strains are negligible in the wing elements because emus have extremely 109 reduced wings, which have no known function other than occasionally being raised to aid 110 thermoregulation (del Hoyo et al., 1992; Maxwell and Larsson, 2007).

111 Therefore, if laminarity is an adaptation to torsion-induced shear strains, we predict that

112 hindlimb bone laminarity will increase from juveniles to adults. Consistent with this hypothesis, 113 we expect no trend in laminarity in the vestigial wing elements from juveniles to adults.

114 Alternatively, if bone laminarity reflects rapid growth (as has been shown previously in emu), it 115 should be abundant in juveniles and decrease with age as growth slows in adults for all elements. 
116 Incorporating growth rate measurements, direct biomechanical data, and direct histological

117 classification of laminarity makes this study a first of its kind that will be able to clarify the

118 importance of growth and mechanics on vascular canal orientation in emu limbs.

119

120

\section{MATERIALS \& METHODS}

121

This study samples forelimb and hindlimb elements from eight emus ranging in age from

1222 to 60 weeks (Table 1). Birds used in this study were euthanized as part of a previous study

123 (Main and Biewener, 2007) and the selected elements stored frozen. Emus were originally

124 obtained as hatchlings by R.P. Main (at the time at Harvard University) from commercial farms

125 (Songline Emu Farm, Gill, MA, USA; Scattered Oaks Emu Farm, Iola, TX, USA; Deep Hollow

126 Farm, Oakdale, CT, USA) and raised at Harvard University's Concord Field Station (Bedford,

127 MA, USA) under Harvard FAS IACUC approval AEP 23-15. For the first eight weeks of life the

128 emus were held in large indoor enclosures, and then moved into pasture-sized outdoor

129 enclosures. All birds had free access to commercial ratite diet (Mazuri, PMI Nutrition

130 International, LLC, Brentwood, MO, USA) and water. Male and female birds were included

131 based on availability. Emus exhibit a minor degree of sexual dimorphism, with females being

132 slightly larger on average (del Hoyo et al., 1992). The difference in size is not large enough to be

133 considered a confounding factor for this study.

134 As a part of a previous study (Main and Biewener, 2007), each bird was given a single

135 intramuscular injection of xylenol orange $(80 \mathrm{mg} / \mathrm{kg})$ followed by calcein $(30 \mathrm{mg} / \mathrm{kg})$. Injections

136 were given one week apart in birds less than 16 weeks of age and two weeks apart in birds

137 between 16 and 65 weeks of age. Xylenol and calcein are fluorescent labels that are incorporated

138 rapidly into newly mineralizing surfaces of bone at the time of injection (An and Martin, 2003). 
139 Thus, the time elapsed and the space between xylenol and calcein labels allows the calculation of

140 periosteal (radial) growth rate. One week after the last injection, surgery was performed to attach

141 strain gauges to the cranial, caudal, and lateral aspects of the left femur and the cranial, caudal,

142 and medial aspects of the left tibiotarsus. Single element strain gauges were used on the lateral

143 femur and cranial and medial tibiotarsus. Rectangular rosette gauges were used on the cranial

144 and caudal femur and caudal tibiotarsus. Rosette strain gauges allow both tensile and

145 compressive principal strains and their orientations to be measured, and were placed so the

146 central element of the gauge was parallel to the long axis of the bone. One day after surgery, the

147 birds were run on a treadmill over a wide range of speeds and gaits. The raw data produced from

148 the strain gauges were converted from voltage to microstrain using a custom MATLAB program.

149 Shear strains were calculated from the rosette strain gauges using standard equations (Biewener

150 and Dial, 1995). High quality shear strain data were most consistently collected from the caudal

151 cortices of the femur and tibiotarsus and that is what is reported here. Trials in which the birds

152 ran with a duty factor near 0.50 are included in the shear strain analysis (mean \pm SD: $0.50 \pm$

153 0.02). Duty factor is the proportion of the time that the animal's foot spends on the ground

154 during a stride relative to the entire stride time. A duty factor of 0.50 represents the point at

155 which the birds transition to a running gait that incorporates an aerial phase. This is a relatively

156 slow run for emu, but represents the duty factor for which we could maximize the number of

157 animals included in this study based upon successful strain gauge function. Each trial was

158 represented by five footfalls and, generally, two trials were collected for each bird. Following

159 bone strain data collection, animals were euthanized. After death, whole wings were removed

160 from the individuals and stored frozen. Histological sections of the femora and tibiotarsi were

161 prepared (see Main and Biewener, 2007 for details) and shipped with the frozen wings to 
162 Midwestern University.

\section{Histological Preparation}

164 Emu wings were thawed and feathers, skin, muscles, and tendons were reflected to

165 expose the skeletal elements. Both right and left wings were used based on availability. Using

166 digital calipers, total length of each bone was measured and recorded. A 37-mm segment was

167 removed using a Dremel tool from the mid-shaft region of the humerus, ulna, and radius. For two

168 and four week old individuals whole elements were harvested due to their small size. Segments

169 were labeled with permanent marker to maintain orientation. Dissected bone segments were

170 placed in $10 \%$ neutral buffered formalin for fixation and then dehydrated in a graded ethanol

171 series $(70 \%, 85 \%, 100 \%)$ under vacuum. Segments were cleared with a xylene-substitute (Histo-

172 clear; National Diagnostics, Atlanta, Georgia, USA). The bone segments were then vacuum-

173 infiltrated and embedded in glass vials using Osteo-Bed Plus Resin, a two-part methyl

174 methacrylate (Polysciences Inc.). Vials were placed in a $32^{\circ} \mathrm{C}$ bead bath to fully harden.

175 Once the resin hardened, vials were broken and two roughly $800-\mu \mathrm{m}$ transverse sections

176 were cut using a diamond blade saw (Isomet 1000; Buehler, Lake Bluff, Illinois, USA). These

177 sections were attached to frosted glass slides using two-ton epoxy (Devcon, Milpitas, California,

178 USA), keeping consistent spatial orientation. Slides were then ground to a thickness of

$179100 \pm 10 \mu \mathrm{m}$ using a graded scale of grit paper on a stand grinder (Metaserv 250; Buehler, Lake

180 Bluff, Illinois, USA) and coverslipped with Permount (Fisher Scientific). The histological

181 preparation was modified from An and Martin (2003) and closely followed Lee and Simons

182 (2015).

\section{Image Collection}

184 The undecalcified sections contain xylenol (orange) and calcein (green) fluorochromes 
185 that were incorporated into newly mineralizing bone at the time of injection (see above for

186 injection schedule). These fluorochromes create stable long lasting tags (van Gaalen et al., 2010)

187 and were examined under bright-field and fluorescent illumination with a motorized

188 epifluorescent microscope (IX73, Olympus). The xylenol (orange) and calcein (green) tags were

189 revealed using TRITC and FITC filter cubes, respectively, and a multichannel (red, green,

190 bright-field) image of each section was generated with imaging software (cellSens, Olympus).

191 Sufficient optical resolution ( $10 \mathrm{X}$ UPlanAPO $\approx 0.84 \mu \mathrm{m} ; 20 \mathrm{X}$ UPlan S-APO $\approx 0.45 \mu \mathrm{m})$ allowed

192 a dual color-monochrome camera (DP80, Olympus) to capture high quality images $(10 \mathrm{X}=1.02$

$193 \mu \mathrm{m} / \mathrm{pixel} ; 20 \mathrm{X}=0.51 \mu \mathrm{m} / \mathrm{pixel})$.

194 Calculating Bone Laminarity and Radial Growth Rates

195 Bright-field and fluorescent images were obtained from the wing and hindlimb elements

196 (Figs. 1 and 2) and divided into equal octants from the estimated bone centroid. Four octants

197 representing the cardinal anatomical positions (wing elements: cranial, caudal, dorsal, ventral;

198 hindlimb elements: cranial, caudal, lateral, medial) were extracted (Fig. 2). Using ImageJ, each

199 extracted octant was then uncurved using the "Straighten" function. The purpose of straightening

200 was to standardize the periosteal tangent line so that appropriate measurements could be made in

201 classifying the orientation of the vascular canals (Lee and Simons, 2015). To ensure there was

202 minimal deformation of the image during the straightening process, known test angles were

203 placed upon the image and measured in relation to the periosteal surface after the straightening

204 function had been applied. Only those images with an average deformation less than or equal to $20510^{\circ}$ were accepted.

206 Within each of the four octants, the calcein green and xylenol orange tags were outlined

207 with two reference lines. The distance between reference lines was measured at 10 equally 
208 spaced points in each octant. Growth rate was measured by taking the mean distance between

209 consecutive fluorescent tags divided by number of days between injections (Fig. 2C).

210 Degree of laminarity (Laminarity Index, LI) was measured in the interval of bone

211 between the fluorochrome reference lines across all four octants. Using ImageJ, an ellipse was

212 drawn within each in-focus primary vascular canal in the measurement interval (Fig. 2D).

213 Branching canals were separated at branch points and counted individually. Sharply curving

214 canals were treated as branching. The aspect ratio and angle at which the ellipse sat in relation to

215 the straightened periosteal surface was measured. We used the criteria set forth by de Margerie

216 (2002) to classify the orientation of the vascular canals: (1) "circular" (circumferential) canals

217 are oriented parallel $\left(0^{\circ} \pm 22.5^{\circ}\right)$ to the periosteal surface of the bone; (2) radial canals are

218 orthogonal $\left(90 \pm 22.5^{\circ}\right)$ to the periosteal surface; (3) longitudinal canals run parallel to the long

219 axis of the bone and have ellipses with an aspect ratio of less than 3; (4) oblique canals are all

220 other orientations. Only primary vascular canals were measured. Secondary osteons in the

221 sample area were excluded. We used a simple proportion (number of circumferential canals to

222 the total number of canals) to quantify laminarity. To test the growth hypothesis, we used the

223 laminarity index calculated from all sampled octants (Table 2, Table S1). Because consistent

224 high quality shear strain data are only available from the caudal octant, we used the laminarity

225 index calculated from only the caudal octant to test the mechanical hypothesis (Table 3, Table

226 S2).

\section{Robust Principal Components Analysis (RPCA) and Beta Regression}

228 The explanatory variables thought to affect laminarity in the emu show multicollinearity.

229 For example, mass and age covary with each other (Goonewardene et al., 2003) as well as with

230 growth rate (Montes et al., 2005), and shear strain (Main \& Biewener, 2007). If left unaddressed, 
231 multicollinearity can decrease precision and reliability when estimating the effect of one variable

232 while holding the others constant (Fekedulegn et al., 2002). Principal components analysis

233 (PCA) accounts for this multicollinearity by forming new uncorrelated variables (i.e., principal

234 components) that are linear combinations of the original explanatory variables while preserving

235 as much of the original variation as possible (Hammer, Harper \& Ryan, 2001). However, PCA is

236 highly sensitive to variables with large variances and skewed distributions (Hubert, Rousseeuw

237 \& Verdonck, 2009), so we standardized (i.e., centered by the median and scaled by the median

238 absolute deviation) mass, age, growth rate, and shear strain with the function "RobScale"

239 (Signorell, 2019) in R (R Core Team, 2019). This process stabilizes variance and minimizes the

240 effect of absolute scale in the calculation of principal components. Skewed data are often

241 transformed prior to PCA (e.g., logarithmic or Box-Cox), but such transformations may worsen

242 skewness or complicate PCA interpretation (Hubert, Rousseeuw \& Verdonck, 2009). Instead, we

243 performed robust PCA (Hubert, Rousseeuw \& Verdonck, 2009) as implemented by the R

244 package "rospca" (Reynkens, 2018), which is suitable for skewed data. Three datasets were

245 analyzed separately: (1) cardinal octants from hindlimb elements; (2) caudal octants from

246 hindlimb elements; and (3) cardinal octants from forelimb elements. The results of each robust

247 PCA are presented in Table 4.

248 For each dataset, the minimum number of principal components (PCs) was selected to 249 cover approximately $95 \%$ of the observed variance of the original explanatory variables. We 250 assessed the relationship between PC(s) and mean laminarity index (LI) using beta regression as

251 implemented by the R package "gamlss" (Rigby \& Stasinopoulos, 2005). This method is

252 appropriate when the response variable (LI) is a proportion (Warton \& Hui, 2011). To

253 accommodate values of 0 in the caudal hindlimb and cardinal forelimb datasets, LI values were 
254 rescaled to the effective interval of $[0.005,0.995]$ (Smithson \& Verkuilen, 2006). The logit link

255 function was used to connect mean LI to a linear combination of the PCs. Pseudoreplication is a

256 concern because different bone elements were sampled from the same individual (Hurlbert,

257 1984; Gillies et al., 2006; Lee \& O'Connor, 2013; Jordan, 2018), so we combined the logit link

258 function with a random-intercept model as follows:

$$
\mu_{\text {logit }(L I)}=\beta_{0}+\beta_{1} P C_{1}+\beta_{2} P C_{2}+\beta_{3} \text { Element }+\gamma
$$

260

where $P C$ is the principal component, $\beta$ is regression coefficient, Element is a dummy variable

261 coding for element type, $\gamma$ is the random-intercept effect of "specimen ID", and $\mu_{\text {logit }(L I)}$ is the

262 logit link function for the mean of LI (Ferrari \& Cribari-Neto, 2004).

For each cardinal dataset, we evaluated two models. The first model includes PC 1 as the

sole predictor given that it accounted for approximately $95 \%$ of the variance in the original

explanatory variables. The second model adds element type as a dummy variable. For the caudal dataset, PC 1 and PC 2 covered at least $95 \%$ of the variance in the original explanatory variables.

Therefore, we evaluated six models. The first three models involve PC 1 and PC 2 individually as sole predictors as well as together in additive combination. The remaining three models add element type as a dummy variable (Table 5). The small-sample correction of Akaike's Information Criterion $\left(\mathrm{AIC}_{\mathrm{c}}\right)$ (Hurvich \& Tsai, 1989) was used to compare models within each dataset. In general, the best supported model has the lowest $\mathrm{AIC}_{\mathrm{c}}$ value (Burnham \& Anderson, 2002). Relative support between the best and alternative models was assessed with difference

$273\left(\Delta \mathrm{AIC}_{\mathrm{c}}\right)$ values. Alternative models with $\Delta \mathrm{AIC}_{\mathrm{c}}$ values greater than 3 , which is equivalent to a $p$ 274 value of 0.051 (Taper, 2004), were rejected as having weak support. Raw data and R script for 275 analyses can be found in the Supplementary Files (Table S1, Table S2, Code S1). 


\section{RESULTS}

278 Measured growth rates ranged from $1.3 \mu \mathrm{m} /$ day (radius of 48 -week-old individual) to $279162.6 \mu \mathrm{m} /$ day (femur of 4.6-week-old individual) (Table 2). Laminarity indices from cardinal 280 octants ranged from 0 to 0.58 (Table 2, Table S1, Fig 3). Laminarity indices from the caudal 281 octant ranged from 0 to 0.81 (Table 3, Table S2).

282

283

284

285

286

287

288

289

290

291

292

293

294

295

296

297

298

299

\section{Regression Analysis of Cardinal Octants from the Femur and Tibiotarsus}

Principal component $(\mathrm{PC}) 1$ (eigenvalue $=8.181)$, consisting of mass, age, and growth rate, accounts for $95 \%$ of the cumulative variance (Table 4 ). Mass and age loadings have the same sign, whereas growth rate loading has an opposite sign. The loadings suggest that PC 1 represents an "ontogenetic axis" with juvenile features (small size, young age, and rapid growth rate) at one end and adult features (large size, old age, and modest growth rate) at the other (Fig. 4). PC 2 (eigenvalue $=0.403$ ) consists of the residual variation in (i.e., "ontogeny-independent") growth rate and accounts for $4.7 \%$ of the cumulative variance (Table 4 ).

The random-intercept beta regression model without element type as a predictor has overwhelming support (Table 5). It predicts that $\sim 89 \%$ of the variation in laminarity is explained by the "ontogenetic axis" (Table 5). Juvenile features (e.g., small size, young age, and rapid growth rate) are correlated with lower laminarity values, whereas adult features are correlated with higher laminarity values $\left(\mathrm{p}<5.51 \mathrm{e}^{-5}\right.$; Fig. 5).

\section{Regression Analysis of Caudal Octants from the Femur and Tibiotarsus}

Table 4 shows that the first two PCs account for at least $95 \%$ of the cumulative variance $-88 \%$ by PC 1 (eigenvalue $=9.435)$ and $9 \%$ by PC 2 (eigenvalue $=0.989)$. Similar to cardinal octant data, mass, age, and growth rate contribute strongly to PC 1 . Their loadings are also consistent with variation along an "ontogenetic axis" with juvenile features at one end 
300 (small size, young age, and rapid growth rate) and adult features at the other (large size, old age,

301 and modest growth rate). Although strain has a minor contribution to PC 1, it dominates PC 2,

302 which we interpret as a "loading effect axis" (Fig. 6).

303 The model with PC 1 as the sole predictor of caudal octant laminarity has strongest

304 support based on $\triangle \mathrm{AIC}_{\mathrm{c}}$ and explains $78 \%$ of the variation in caudal octant laminarity (Table 5).

305 Caudal and cardinal datasets show slightly different estimates for the coefficient of PC 1, which

306 is consistent with slight inter-octant variation in laminarity. Variation aside, the overall

307 ontogenetic trend is similar: higher laminarity values are correlated with adult features, whereas

308 lower laminarity values are correlated with juvenile features (Fig. 7; $p=0.013$ ). Although shear

309 strain contributes to PC 1 and generally increases along the "ontogenetic axis", the effect is

310 relatively weak. To highlight this, we multiplied the regression coefficient and eigenvectors of

311 PC 1. The resulting standardized coefficients of the original predictors (growth rate $=-0.041$;

312 mass $=0.097$; age $=0.150 ;$ strain $=0.035)$ suggest that the relative effects of growth rate, mass,

313 and age on caudal octant laminarity in the hindlimb are 1.2 to 4.3 times greater than that of

314 strain.

315 The caudal hindlimb dataset does not support the "loading effect axis" (PC 2) as a strong

316 predictor for laminarity. Compared to model 1 (PC 1 as the sole predictor), the remaining

317 alternative models with PC 2 only explain an additional $5-6 \%$ of the variation in caudal

318 hindlimb laminarity. Each of these alternative models has $\Delta \mathrm{AIC}_{\mathrm{C}}$ larger than 3 indicating weak

319 to no support $(p>0.05)$. Furthermore, the model coefficient for PC 2 in model 2 (sole predictor)

320 and model 3 (additive combination with PC 1) is not significant ( $p$-value equals 0.169 and 0.056 ,

321 respectively; Table 5).

322 Regression Analysis of Cardinal Octants from the Humerus, Ulna, and Radius 
324 dominate PC 1 (eigenvalue = 7.977), and this "ontogenetic axis" accounts for $97 \%$ of the

325 cumulative variance (Table 4 , Fig. 8). PC 2 (eigenvalue $=0.187$ ) absorbs residual variation in

326 growth rate and accounts for an additional $2.3 \%$ of the cumulative variance.

Although the model with "ontogenetic axis" (PC 1) as the sole predictor has the best support, it only accounts for $27.7 \%$ of the variation in forelimb laminarity. Moreover, the model coefficient for PC 1 is not significant ( $p=0.089$; Table 5).

\section{DISCUSSION}

\section{Does bone laminarity reflect fast growth?}

The highest periosteal growth rate in all elements was found in the femur of the 4.6-week

334 old individual (Table 2). As expected, hindlimb elements had higher growth rates than forelimb

335 elements, reaching a maximum of $163 \mu \mathrm{m} /$ day in the femur and $99 \mu \mathrm{m} /$ day in the tibiotarsus. The

336 humerus grew the fastest of the wing elements, reaching a maximum rate of $25 \mu \mathrm{m} /$ day measured

337 in the 2.3 and 4.6 week old individuals. Birds older than 8 weeks experienced a drastic decrease 338 in bone growth rate in both hindlimb and forelimb elements. Previous analysis of emu somatic 339 growth rate (increase in body mass) showed the maximum rate of growth (inflection point) to be 340 about 15-17 weeks of age (Goonewardene et al., 2003). Our results reveal that age at maximum

341 bone growth (approximately 5 weeks) precedes the somatic growth inflection, similar to other 342 vertebrates (Lee et al., 2013). Therefore, caution is warranted when inferring somatic life-history 343 milestones, such as growth spurts, solely from skeletal data.

344 Principal components analysis reveals a large proportion of variance lies along an 345 "ontogenetic axis" (Figs. 4, 6, 8). One end of the axis is represented by juvenile traits such as 
346 small size, young age, and rapid growth, whereas adult traits such as large size, old age, and

347 modest growth characterize the other end. This "ontogenetic axis" has a significant influence on

348 laminarity in the femur and tibiotarsus (Figs. 5, 7), whether analyzed in cardinal octants (p <

$3490.001)$ a single octant $(\mathrm{p}=0.013)$. Elevated laminarity in the hindlimb appears correlated with

350 adult features, including modest growth rate. This relationship is consistent with findings in the

351 king penguin that also reported laminar bone to be associated with modest growth rates in four

352 limb bones: femur, tibiotarsus, humerus, and radius (de Margerie et al., 2004). More recently, a

353 study using microCT to assess three-dimensional vascular canal orientation in the humerus and

354 femur of growth-controlled broiler chickens also found elevated laminarity in a slow-growing

355 (feed-restricted) group (Pratt and Cooper, 2018). Interestingly, the effect of the "ontogenetic

356 axis" on laminarity in the wing elements is weak $(\mathrm{p}=0.089)$, only explaining $27.7 \%$ of variation

357 (Fig. 9). The weakened "ontogenetic axis" in wing bone laminarity is consistent with relaxed

358 selection on the vestigial wing leading to increased anatomical variability in the species

359 (Maxwell \& Larsson, 2007).

Notably, our results differ from those previously reported for young emu bones in which

361 laminar and reticular bone was found in the fastest growing hindlimb bones (Castanet et al.,

362 2000). In particular, Castanet et al. (2000) found laminar bone to be most abundant in the femur

363 and tibiotarsus of emu less than 2 months of age, which corresponds to the youngest individuals

364 in our study. Based on reported body masses, the emus included in our study were about 2-3

365 times heavier than the emus in the Castanet et al. (2000) study for a given age (Table 1). The

366 reason for the differences in size and ontogenetic patterns for bone vascularity types between

367 these two emu samples remain unknown, but could be related to genetic, dietary, or rearing

368 conditions between the two groups. If laminarity is associated with lower growth rates, the 
369 youngest emus we studied may have been growing too fast for laminar bone to form. The highest

370 growth rate measured was in the femur of the 4.6-week-old bird $(162.62 \mu \mathrm{m} /$ day $)$, which was

371 about twice the highest growth rate found in the femoral reticular bone tissue reported in the

372 prior study $(89.4 \mu \mathrm{m} /$ day $)$. Our study did not specifically address reticular bone, but by taking

373 the proportion of oblique vascular canals (a "reticular index"), we found the amount of reticular

374 bone in the fastest growing individual to be low in the hindlimb elements (femur and tibiotarsus:

375 0.17), and moderate to high in the wing elements (humerus: 0.62, ulna: 0.58, radius: 0.45). This

376 result is, at least, consistent with the previous study because Castanet et al. (2000) found reticular

377 bone to be more abundant in the humerus. The data analysis in the earlier emu study (Castanet et

378 al., 2000) was conducted before a more rigorous method for quantifying canal orientation was

379 developed (de Margerie, 2002), which may contribute to the observed differences between the

380 two separate emu populations. Regardless, the results of the present study do not support the

381 hypothesis that elevated laminarity reflects rapid growth in the emu and instead link elevated

382 laminarity with more modest growth rates.

\section{Does bone laminarity reflect biomechanical load?}

Robust PCA is consistent with previous scaling analysis showing that shear strains in the

385 femur and tibiotarsus of the emu increase with growth (Main \& Biewener, 2007). Shear strain

386 covaries with mass, age, and growth rate along an "ontogenetic axis" such that juveniles

387 experience smaller shear strains in the caudal octants, whereas adults experience larger strains

388 (Table 4; Fig.6). However, shear strain contributes comparatively less to the "ontogenetic axis"

389 than the other covariates. Consequently, it has a correspondingly minor effect on caudal octant

390 laminarity in the hindlimb. Indeed, transformation of the effect of the "ontogenetic axis" on

391 laminarity back into the scale of the actual covariates reveals that the standardized effects of age 
$392(0.150)$, mass $(0.097)$, and growth rate $(-0.041)$ are relatively larger than that of shear strain

393 (0.035). Elevated laminar bone tissue, in combination with increased bone mineralization and

394 decreased bone curvature during growth, may have collectively helped mitigate shear strains

395 despite the large increase in mass (Main and Biewener, 2007).

396

Residual variation in shear strain that is not accounted for by the "ontogenetic axis"

397 forms a "loading effect axis" (Table 4; Fig. 6). However, this effect does not correlate with

398 laminarity either as the sole predicator $(\mathrm{p}=0.169)$ or in additive combination with ontogeny $(\mathrm{p}=$

399 0.056). Put together, the results clearly show that ontogenetic factors largely influence the

400 formation of laminar bone in the caudal hindlimb of the emu, although torsion-induced shear

401 strain is a minor additional factor.

402 The weak association between laminarity and shear strain limits the predictive potential

403 of this relationship. Our results for emu hindlimb bones are consistent with previous studies of

404 other limb elements presumably loaded in torsion. For example, when comparing wings of

405 similar shape, laminarity in wing bones can be similar despite differences in presumed

406 biomechanical load associated with unique primary flight modes (Simons and O'Connor, 2012;

407 Marelli and Simons, 2014). In addition, preferred flight mode may only have subtle effects on

408 overall loading of the bones, with the dominant loads being the high strains present during take-

409 off (Biewener and Dial, 1995). Furthermore, despite sharing with birds convergent features

410 related to powered-flight such as torsionally loaded bone with relatively thin cortical walls

411 (Swartz, Bennett \& Carrier, 1992), bone mineral density (Dumont, 2010), and metabolic rate

412 (e.g., Maina, 2000), bats lack laminar bone entirely (Lee \& Simons, 2015; Pratt et al., 2018).

413 Instead, they have bones that are poorly-vascularized with a parallel-fibered matrix. Because that

414 histology tends to grow very slowly in other species [e.g., $<5 \mu \mathrm{m} \mathrm{d}^{-1}$ (de Margerie, Cubo \& 
415 Castanet, 2002; Castanet et al., 2004)], Lee and Simons (2015) speculated that bats do not grow

416 fast enough to form laminar bone. Indeed, somatic growth is approximately four times slower in

417 bats than in birds of comparable size (Lee \& Simons, 2015). Caution is warranted, however, as

418 we show in the emu that interchanging somatic and skeletal growth may be misleading.

419 Whatever the actual cause is, the evidence is clear that elevated laminarity is not a prescriptive

420 feature of torsionally loaded bone.

421 In this study, age groups are represented by one individual, with the exceptions of the

422 youngest and oldest age groups that contain two. A larger sample of individuals in each age

423 group would allow for investigation of how individual variation may or may not affect the

424 relationship between LI, shear strain, and growth rate. Laminarity indices can be quite variable

425 among individuals in some species. The pigeon humerus, which has been shown to experience

426 large torsional loads, has been documented to exhibit both high and low laminarity in different

427 individuals ( Lee and Simons, 2015; Ourfalian et al., 2016; Skedros and Doutré, 2019).

428 Similarly, a pooled sample of humeri from eight Red-tailed hawks show LI values that range

429 from 0.30-0.70 (Simons and O’Connor, 2012; Marelli and Simons, 2014). Whether these

430 variability patterns are biological or methodological is unclear. Laminarity measured on a

431 histological section is a 2-dimensional representation of a 3-dimensional meshwork of vascular

432 canals in cortical bone. This research is limited by the assumption that one or two closely placed

433 mid-shaft histological sections are an accurate representation of vascular canal structure.

434 MicroCT-based assessment of the three-dimensional network of vascular canals suggests that

435 traditional 2D histological methods may overestimate LI, but also recognizes that these

436 differences may be methodological (Pratt and Cooper, 2017; Pratt et al., 2018). Certainly, future

437 studies should continue to use microCT to assess how well laminarity measured on histological 
438 sections represents actual biological structure. In addition, the torsional resistance in bones may

439 more likely be linked to the specific orientation of another histological feature: collagen fibers.

440 Collagen fiber orientation (CFO) has been shown to reflect principle strain distributions (Riggs

441 et al., 1993; Skedros and Hunt, 2004; Skedros et al, 2004; Skedros and Doutré, 2019). Analysis

442 of CFO is beyond the scope of the current study. However, given the known positive correlation

443 between transversely oriented collagen fibers and bone laminarity (de Margerie et al., 2005), we

444 would expect a similar pattern for the femora and tibiotarsi examined here.

445 Although there is no direct biomechanical data for the forelimb elements of these birds,

446 the wing elements presumably experience minimal loading. The emu wing is extremely reduced

447 in size, even when compared to other ratites, and has almost no observed function (del Hoyo et

448 al., 1992). Wing muscles of emu contain primarily slow acting tonic muscle fibers that may not

449 allow much wing movement (Maxwell and Larsson, 2007), which suggests the underlying wing

450 elements would experience minimal biomechanical loading. Despite the assumption that the emu

451 wing is under minimal load, a moderate to high degree of laminarity was found in at least the

452 humerus and ulna (Table 2). This laminarity can be attributed to the modest bone growth rate

453 observed in the wing elements and/or to the third factor affecting bone microstructure:

454 phylogenetic relationships. Within the paleognaths, it has been hypothesized that at least three

455 independent flight losses have occurred, with only one order (the tinamous) still retaining the

456 ability to fly (Harshman et al., 2008; Mitchell et al., 2014). The moderate/high wing bone

457 laminarity may be a feature of the flighted common ancestor of paleognaths that is retained in the

458 flightless descendants. Indeed, significant phylogenetic signal has been found in some

459 osteohistological features in a sample of paleognaths (Legendre et al., 2014). Future studies

460 should investigate the histological and in vivo loading of the flighted relatives of emus to better 
461 understand the potential influence of phylogeny on bone laminarity.

462

463 CONCLUSIONS

464 In the emu limb skeleton, ontogenetic factors such as size, age, and growth rate have 465 major effects on vascular canal orientation. The effect of shear strain is relatively weak and 466 suggests that laminar bone is not a good predictor of torsional loading. Even though the forelimb 467 elements likely experience minimal loading, the humerus and ulna show wide variation in 468 laminarity, perhaps due to relaxed selection. Future studies should investigate laminarity in other 469 palaeognathous birds to better understand the effects phylogeny, ontogeny, and torsional loading 470 have on bone laminarity. Other future work should focus on the experimental manipulation of

471 biomechanical loads to observe the effects on vascular canal orientation in limb bones and to 472 better understand to what extent torsional load influences the development of limb bone 473 laminarity. It is also important that variation found between different populations be addressed 474 and studied further. Emu body mass growth rates vary among populations (e.g. Goonewardene et 475 al., 2003), but it is unknown to what extent laminar bone also varies with environmental, dietary, 476 or genetic factors. This study has shown that in emu limb bones, laminarity reflects a complex 477 interplay of ontogeny and biomechanical loads.

478

479 ACKNOWLEDGEMENTS

480 The authors would like to thank K Ezell for assistance with histological preparation and imaging.

481 We are grateful for free access to the microscopes in the Microscopy Core Facility at

482 Midwestern University. We thank Andrew Biewener and the graduate students and postdocs at 483 the Concord Field Station (2002-2006) for assistance with bone strain data collection. We thank 
484 reviewers Edina Prondvai and Jorge Cubo for useful comments that improved the manuscript.

485

486 


\section{REFERENCES}

488 Amprino R. 1947. La structure du tissu osseux envisagee comme expression de differences dans

489 lavitesse de l'accroissement. Archives de Biologie 58:315-330.

490 An YH, Martin KL. 2013. Handbook of histology methods for bone and cartilage. Humana

$491 \quad$ Press; $1^{\text {st }}$ edition.

492 Biewener AA, Dial KP. 1995. In vivo strain in the humerus of pigeons (Columba livia). Journal 493 of Morphology 225:61-75. DOI 10.1002/jmor.1052250106.

494 Burnham KP, Anderson DR. 2002. Model selection and multimodel inference: a practical 495 information-theoretic approach. New York: Springer-Verlag.

496 Carrano MT, and Biewener AA. 1999. Experimental alteration of limb posture in the chicken

497 (Gallus gallus) and its bearing on the use of birds as analogs for dinosaur locomotion. 498 Journal of Morphology 240(3):237-249.

499 Castanet J, Curry-Rogers K, Cubo J, Boisard JJ. 2000. Periosteal bone growth rates in extant 500 ratites (ostriche [sic] and emu). Implications for assessing growth in dinosaurs. Comptes 501 Rendus de l'Academie des Sciences Serie III Sciences de la Vie 323:543-550. DOI

$502 \quad$ 10.1016/S0764-4469(00)00181-5.

503 Castanet J, Croci S, Aujard F, Perret M, Cubo J, de Margerie E. 2004. Lines of arrested growth 504 in bone and age estimation in a small primate: Microcebus murinus. Journal of Zoology $505 \quad 263: 31-39$.

506 Curry JD. 2002. Bones: Structure and Mechanics. Princeton and University Press.

507 de Ricqlès AJ, Meunier FJ, Castanet J, Francillon-Vieillot H. 1991. Comparative microstructure 508 of bone. In: Hall BK, ed. Bone, volume 3: bone matrix and bone specific products. Boston: $509 \quad$ CRC Press, 1-78. 
510 de Margerie E. 2002. Laminar bone as an adaptation to torsional loads in flapping flight. Journal

511 of Anatomy 201:521-526. DOI 10.1046/j.1469-7580.2002.00118.x.

512 de Margerie E, Cubo J, Castanet J. 2002. Bone typology and growth rates: testing and

513 quantifying 'Amprino's rule' in the mallard (Anas platyrhynchos). Comptes Rendus

514 Biologies 325:221-230. DOI 10.1016/S1631-0691(02)01429-4.

515 de Margerie E, Robin JP, Verrier D, Cubo J, Groscolas R, Castanet J. 2004. Assessing a

516 relationship between bone microstructure and growth rate: a fluorescent labelling study in the

517 king penguin chick (Aptenodytes patagonicus). Journal of Experimental Biology 207:869-

518 879. DOI 10.1242/jeb.00841.

519 de Margerie E, Sanchez S, Cubo J, Castanet J. 2005. Torsional resistance as a principal

520 component of the structural design of long bones: comparative multivariate evidence in birds.

$521 \quad$ Anatomical Record 282A:49-66.

522 del Hoyo J, Elliot A, Sargatal J. eds. 1992. Handbook of the Birds of the World. Volume 1. Lynx

523 Edicions, Barcelona.

524 Dumont ER. 2010. Bone density and the lightweight skeletons of birds. Proceedings of the Royal 525 Society B 277:2193-2198. DOI: 10.1098/rspb.2010.0117.

526 Fekedulegn BD, Colbert JJ, Hicks Jr. RR, Schuckers ME. 2002. Coping with multicollinearity:

527 an example on application of principal components regression in dendroecology. Newtown

528 Square, Pennsylvania: U.S. Department of Agriculture, Forest Service, Northeastern

529 Research Station. DOI: 10.2737/NE-RP-721

530 Ferrari S, Cribari-Neto F. 2004. Beta regression for modelling rates and proportions. Journal of

$531 \quad$ Applied Statistics 31(7):799-815. DOI: 10.1080/0266476042000214501.

532 Francillon-Vieillot H, de Buffrénil V, Castanet J, Géraudie J, Meunier FJ, Sire JY, Zylberberg L, 
de Ricqlès A. 1990. Microstructure and mineralization of vertebrate skeletal tissues. In:

534 Carter JG, ed. Skeletal Biomineralization: Patterns, Processes and Evolutionary Trends. Volume 1. New York: Van Nostrand Reinhold, 471-548.

536 Gillies CS, Hebblewhite M, Nielsen SE, Krawchuk MA, Aldridge CL, Frair JL, Saher DJ, 537 Stevens CE, Jerde CL. 2006. Application of random effects to the study of resource selection 538 by animals. Journal of Animal Ecology 75:887-898. DOI: 10.1111/j.13652656.2006.01106.x.

540 Goonewardene LA, Wang Z, Okine E, Zuidhof MJ, Dunk E, Onderka D. 2003. Comparative 541 growth characteristics of Emus (Dromaius novaehollandiae). The Journal of Applied Poultry $542 \quad$ Research 12(1):27-31.

543 Hammer Ø, Harper DAT, Ryan PD. 2001. PAST: Paleontological statistics software package for $544 \quad$ education and data analysis. Palaeontologia Electronica 4:9.

545 Harshman, J, Braun EL, Braun MJ. 2008. Phylogenomic evidence for multiple losses of flight in 546 ratite birds. Proceedings of the National Academy of Sciences of the United States of America $547 \quad 105: 13462-13467$.

548 Hubert M, Rousseeuw P, Verdonck T. 2009. Robust PCA for skewed data and its outlier map. 549 Computational Statistics \& Data Analysis 53:2264-2274. DOI: 10.1016/j.csda.2008.05.027. 550 Hurlbert SH. 1984. Pseudoreplication and the design of ecological field experiments. Ecological $551 \quad$ Monographs 54:187-211. DOI: 10.2307/1942661.

552 Hurvich CM, Tsai C-L. 1989. Regression and time series model selection in small samples.

553 Biometrika 76:297-307.

554 Jordan CY. 2018. Population sampling affects pseudoreplication. PLoS Biology 16:e2007054.

555 DOI: 10.1371/journal.pbio.2007054. 
556 Lee AH, O’Connor PM. 2013. Bone histology confirms determinate growth and small body size

557 in the noasaurid theropod Masiakasaurus knopfleri. Journal of Vertebrate Paleontology

$558 \quad 33: 865-876$. DOI: 10.1080/02724634.2013.743898.

559 Lee AH, Simons ELR. 2015. Wing bone laminarity is not an adaptation for torsional loading in $560 \quad$ bats. PeerJ 3:e823. DOI 10.7717/peerj.823.

561 Legendre LJ, Bourdon E, Scofield, RP, Tennyson A, Lamrous H, de Ricqlès AJ, Cubo J. 2014.

562 Bone histology, phylogeny, and palaeognathous birds (Aves: Palaeognathae). Biological 563 Journal of the Linnean Society 112:688-700.

564 Main RP, Biewener AA. 2007. Skeletal strain patterns and growth in the emu hindlimb during 565 ontogeny. Journal of Experimental Biology 20:2676-2690.

566 Maina JN. 2000. What it takes to fly: the structural and functional respiratory refinements in 567 birds and bats. Journal of Experimental Biology 203:3045.

568 Marelli CA, Simons ELR. 2014. Microstructure and cross-sectional shape of limb bones in Great 569 Horned Owls and Red-tailed Hawks: how do these features relate to differences in flight and $570 \quad$ hunting behavior? PloS one 9(8):e106094.

571 Maxwell EE, Larsson HCE. 2007. Osteology and myology of the wing of the emu (Dromaius 572 novaehollandiae), and its bearing on the evolution of vestigial structures. Journal of 573 Morphology 268:423-441. DOI: 10.1002/jmor.10527.

574 Mitchell KJ, Llamas B, Soubrier J, Rawlence NJ, Worthy TH, Wood J, Cooper A. 2014. Ancient 575 DNA reveals elephant birds and kiwi are sister taxa and clarifies ratite bird evolution.

$576 \quad$ Science 344(6186):898-900

577 Montes L, de Margerie E, Castanet J, de Ricqlès AJ, Cubo J. 2005. Relationship between bone 578 growth rate and the thickness of calcified cartilage in the long bones of the Galloanserae 
(Aves). Journal of Anatomy 206:445-452.

580 Ourfalian RM, Ezell K, Lee AH. 2016. Development of wing bone laminarity in the pigeon. The 581 Official Journal of the Federation of American Societies for Experimental Biology

\section{3} $30: 779.12$.

Padian K. 2013. Why study the bone microstructure of fossil tetrapods? In: Padian K, Lamm ET, eds. Bone Histology of Fossil Tetrapods: Advancing Methods, Analysis, and Interpretation. California: University of California Press, 1-11.

Pratt IV, Cooper DML. 2017. A method for measuring the three-dimensional orientation of cortical canals with implications for comparative analysis of bone microstructure in

\section{1}

592 vertebrates. Micron 92:32-38.

Pratt IV, Cooper DML. 2018. The effect of growth rate on the three-dimensional orientation of vascular canals in the cortical bone of broiler chickens. Journal of Anatomy 233:531-541.

Pratt IV, Johnston JD, Walker E, Cooper DML. 2018. Interpreting the three-dimensional orientation of vascular canals and cross-sectional geometry of cortical bone in birds and bats. Journal of Anatomy 232(6):931-942.

R Development Team. 2019. R: A language and environment for statistical computing. Vienna,

596 Reynkens T. 2018. rospca: Robust Sparse PCA using the ROSPCA Algorithm. R package 597 version 1.0.4.

598 Rigby RA, Stasinopoulos DM. 2005. Generalized additive models for location, scale and shape. $599 \quad$ Applied Statistics 54:507-554.

600 Riggs CM, Lanyon LE, Boyde A. 1993. Functional associations between collagen fibre 601 orientation and locomotor strain direction in cortical bone of the equine radius. Anatomy and 

Embryology 187:231-238.

603 Rubin CT, Lanyon LE. 1985. Regulation of bone mass by mechanical strain magnitude. 604 Calcified tissue international 37(4):411-417.

605 Signorell A. 2019. DescTools: Tools for descriptive statistics. R package version 0.99.28

606 Simons ELR, O’Connor PM. 2012. Bone laminarity in the avian forelimb skeleton and its 607 relationship to flight mode: testing functional interpretations. The Anatomical Record 608 295:386-396. DOI 10.1002/ar.22402.

609 Skedros JG, Hunt KJ. 2004. Does the degree of laminarity correlate with site-specific differences 610 in collagen fibre orientation in primary bone? An evaluation in the turkey ulna diaphysis. 611 Journal of Anatomy 205:121-134.

612 Skedros JG, Hunt KJ, Bloebaum RD. 2004. Relationships of loading history and structural and 613 material characteristics of bone: development of the mule deer calcaneus. Journal of $614 \quad$ Morphology 259(3):281-307.

615 Skedros JG, Doutré MS. 2019. Collagen fiber orientation pattern, osteon morphology and 616 distribution, and presence of laminar histology do not distinguish torsion from bending in at 617 and pigeon bones. Journal of Anatomy Early View. doi.org/10.1111/joa.12981

618 Smithson M, Verkuilen J. 2006. A better lemon squeezer? Maximum-likelihood regression with 619 beta-distributed dependent variables. Psychological Methods 11:54-71. DOI: 10.1037/1082$620989 X .11 .1 .54$

621 Swartz SM, Bennett MB, Carrier DR. 1992. Wing bone stresses in free flying bats and the 622 evolution of skeletal design for flight. Nature 359:726-729.

623 Taper ML. 2004. Model identification from many candidates. In: Taper ML, Lele SR eds. The $624 \quad$ Nature of Scientific Evidence: Statistical, Philosophical, and Empirical Considerations. 
625 Chicago, Illinois: University of Chicago Press, 488-524.

626 van Gaalen SM, Kruyt M, Geuze RE, de Bruijn JD, Alblas J, Dhert WJ. 2010. Use of

627 fluorochrome labels in in vivo bone tissue engineering research. Tissue Engineering Part B:

628 Reviews 16: 209-217.

629 Warton DI, Hui FKC. 2011. The arcsine is asinine: the analysis of proportions in ecology.

630 Ecology 92(1):3-10.

631 Williams B, Waddington D, Murray DH, Farquharson C. 2004. Bone strength during growth:

632 influence of growth rate on cortical porosity and mineralization. Calcified Tissue

$633 \quad$ International 74:236-245.

634 
Figure 1

Representative histological sections of emu femora, tibiotarsi, and humeri from a range of ages.

2.3 weeks ( $A, B, C), 8.1$ weeks (D, E), 12 weeks (F), 16 weeks $(G, H, I), 60$ weeks ( $L, J, K)$.

Femora (A, D, G, J), tibiotarsus (B, E, H, K) and humeri (C, F, I, L). Scale bars equal $1000 \mu \mathrm{m}$ for femora and tibiotarsi, and $250 \mu \mathrm{m}$ for humeri. Bright field images of non-straightened caudal or medial octants. 

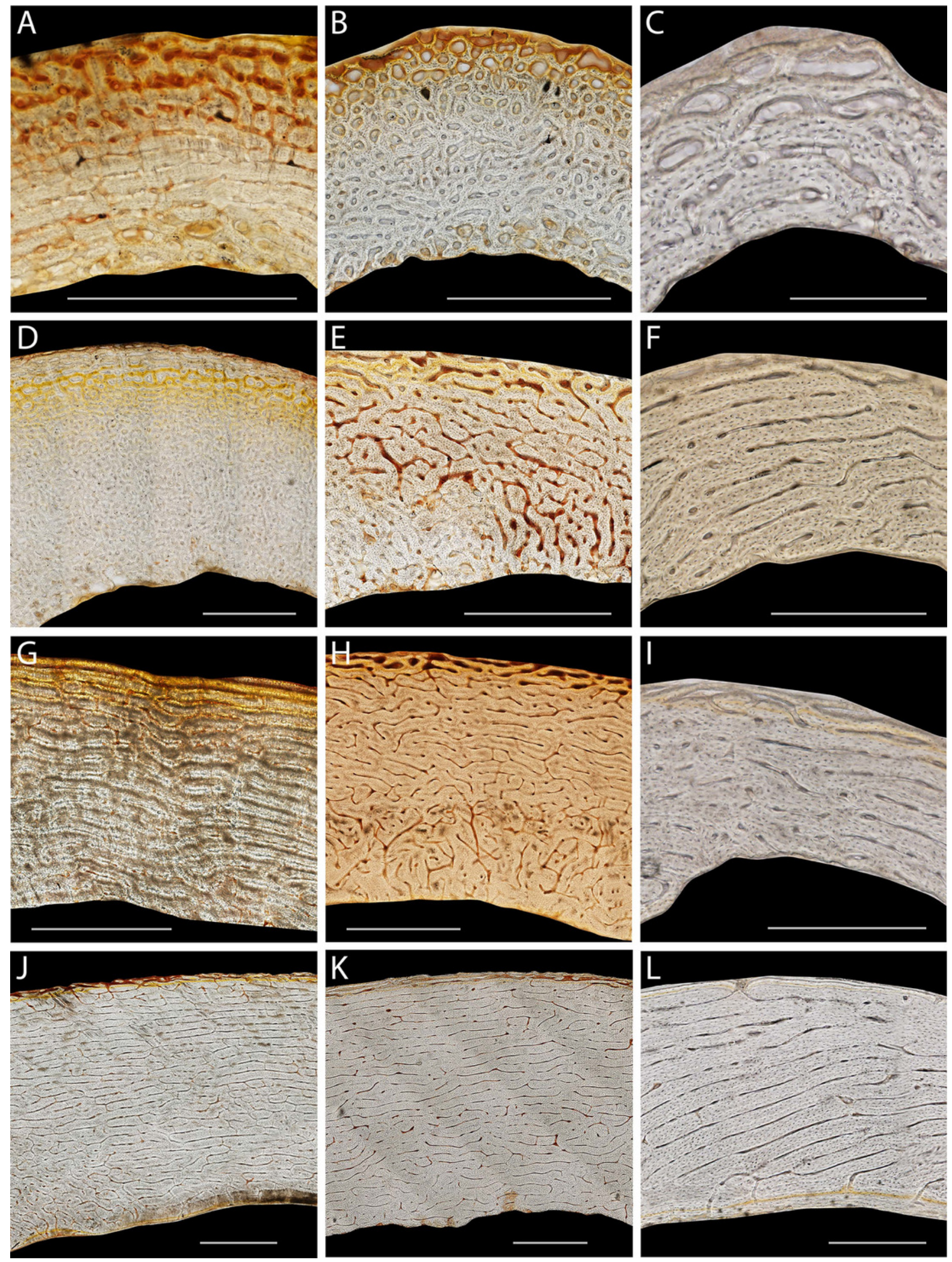


\section{Figure 2}

Sampling methods for growth rate and laminarity measures.

(A) Gray shading indicates the four octants (wing elements: cranial, caudal, dorsal, ventral; hindlimb elements: cranial, caudal, lateral, medial) sampled on each cross-section. (B) Each octant was isolated, straightened, and a sample area indicated: between fluorochrome reference lines. (C) On fluorescent images, growth rate was measured by taking the mean distance (white arrow) between the periosteal extent of the xylenol (red) and calcein (green/yellow) tags divided by number of days between injections. (D) Laminarity was measured by approximating each in-focus primary vascular canal with the best-fitting ellipse, using the best-fitting ellipse to categorize canal orientations, and calculating the proportion of circumferential canals. (Tibiotarsus 17, 4.6 wks). 


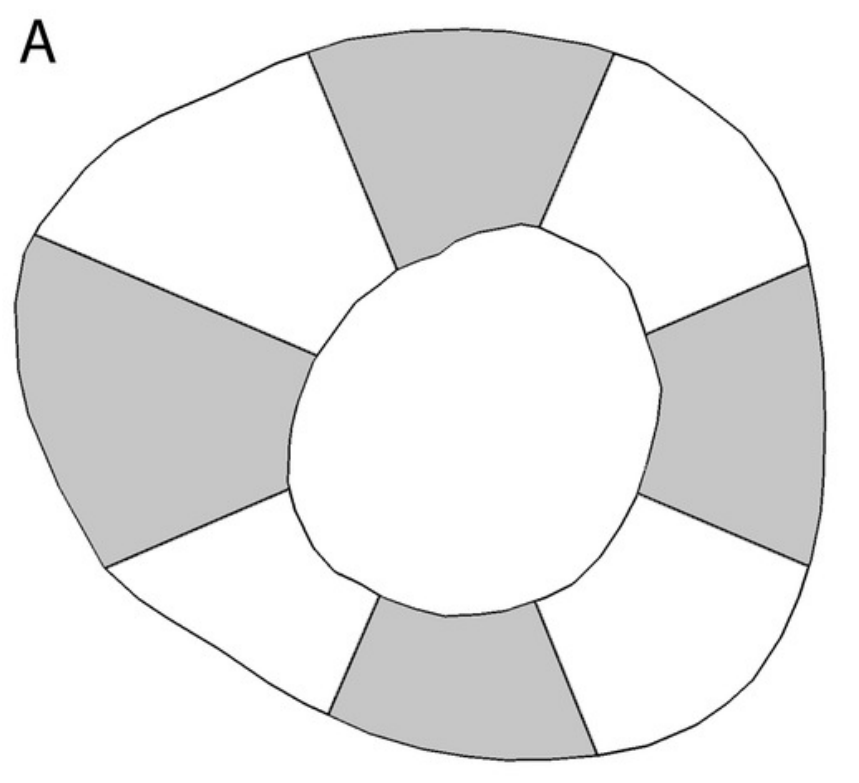

B
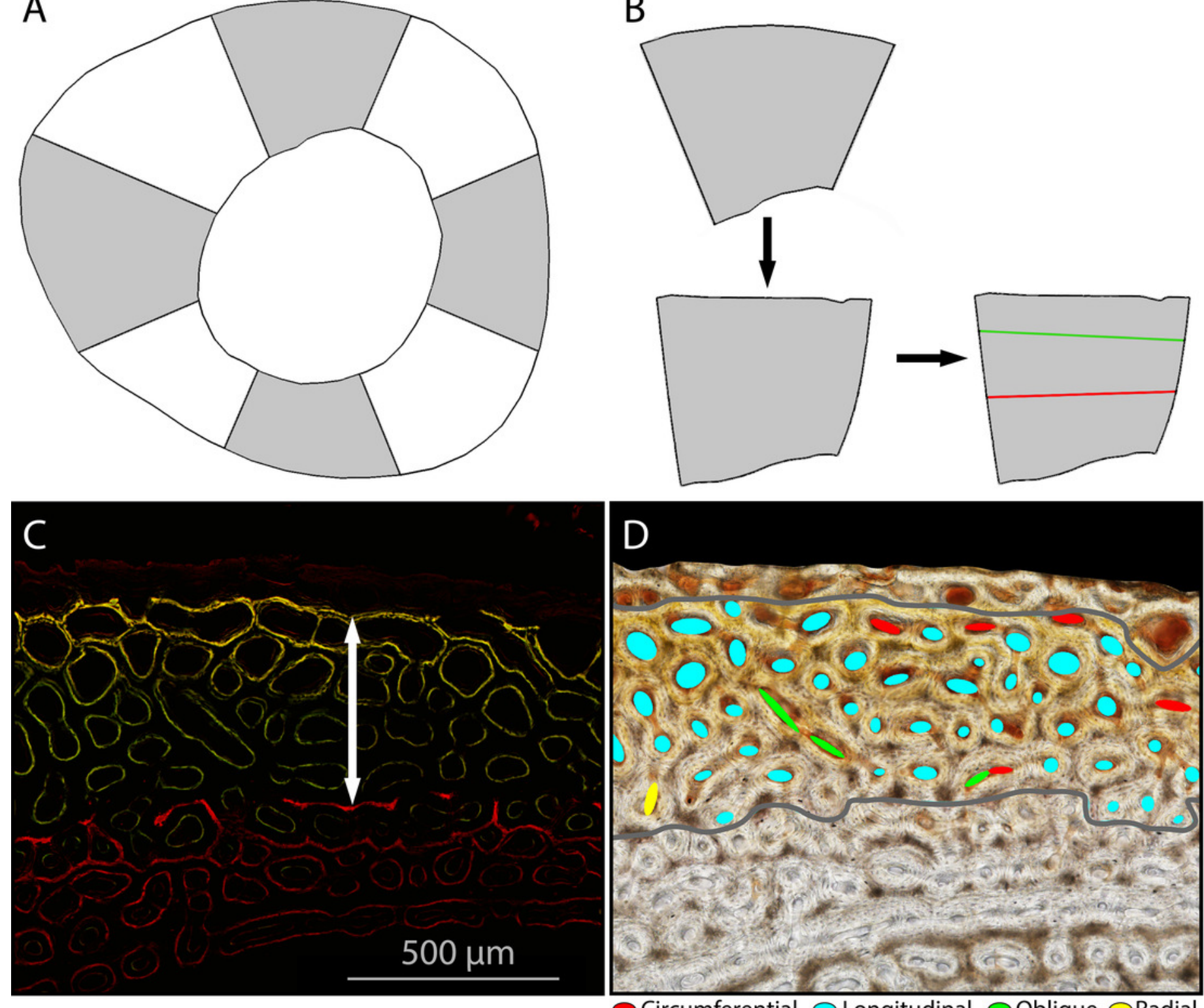

Circumferential $\bigcirc$ Longitudinal $\bigcirc$ Oblique $\bigcirc$ Radial 


\section{Figure 3}

Laminarity Indices for the forelimb and hindlimb bones included in this study.

Laminarity indices (LI) measured from the cardinal octants for each bone (Fem=femur, Tbt= tibiotarsus, Hum=humerus, Ulna, Rad=radius) from specimens (A) $15-2$ week, (B) 1c - 2 week, (C) 17 - 5 week, (D) 14b - 8 week, (E) 16 - 12 week, (F) 2a - 16 week, (G) 21 - 48 week, and (H) 23 - 60 week. LI was measured between fluorochrome reference lines on all sampled octants.

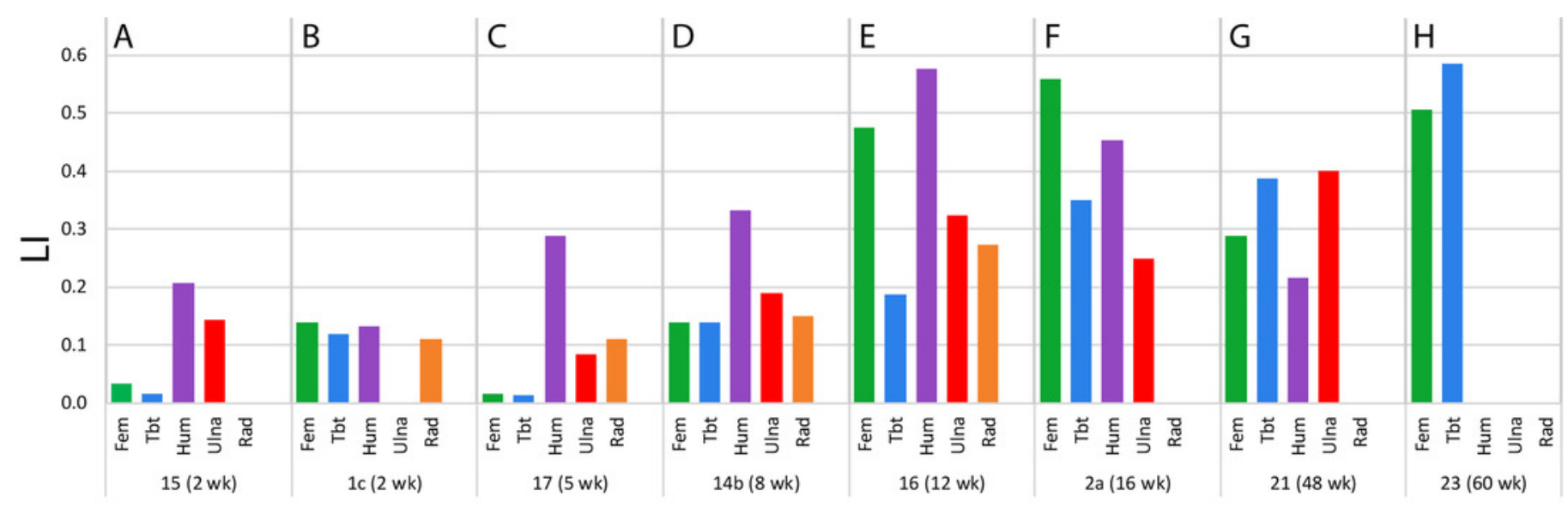


Figure 4

Robust principal components analysis of the cardinal octants from the femur and tibiotarsus.

An "ontogenetic axis" (PC 1) accounts for 95\% of the variance with juvenile features to the left (small size, young age, and rapid growth) and adult features to the right (large size, old age, and modest growth). Residual variation in growth rate is absorbed into PC 2 , which accounts for another $4.7 \%$ of the cumulative variance.

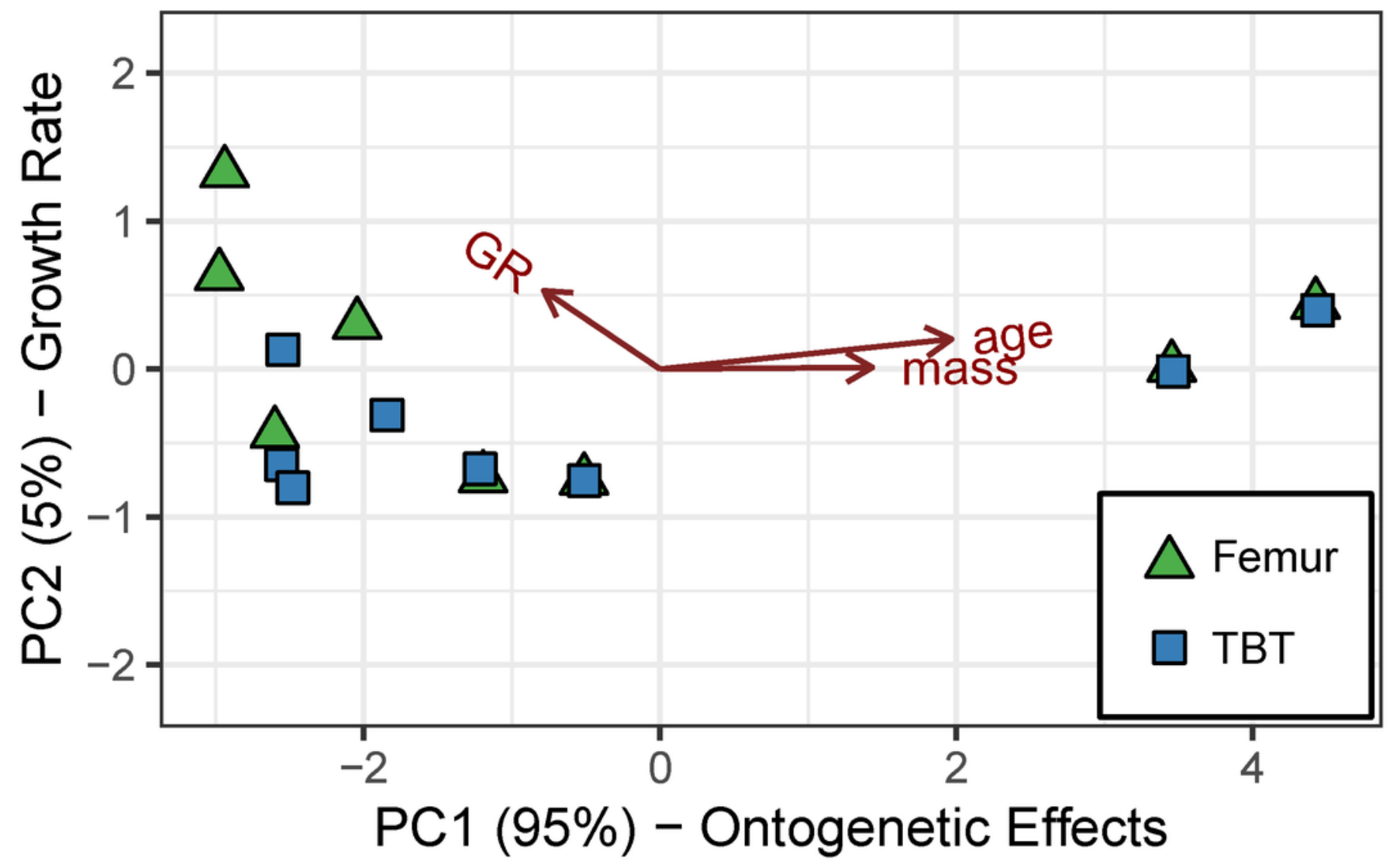




\section{Figure 5}

Effect of the "ontogenetic axis" (PC 1) on laminarity (LI) in the cardinal octants of the hindlimb.

Random-intercept beta regression reveals that the "ontogenetic axis" (PC 1) accounts for $89 \%$ of the variation in laminarity from the cardinal octants of femur (green triangles) and tibiotarsus (blue squares). Elevated laminarity values are strongly correlated with adult features such as large size, old age, and modest growth rate $\left(p<5.51 e^{-5}\right)$. 


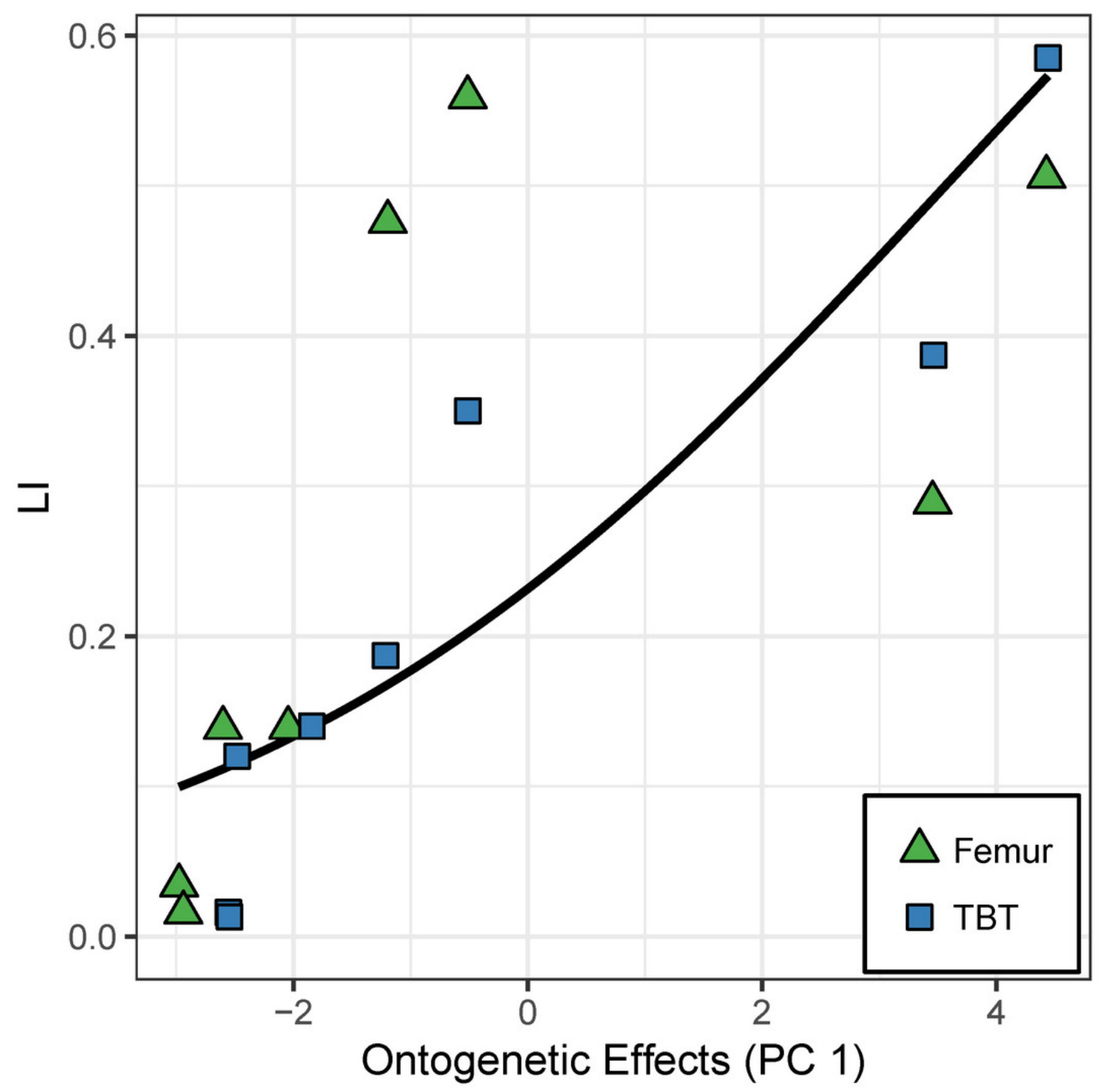


Figure 6

Robust principal components analysis of the caudal octants from the femur and tibiotarsus.

An "ontogenetic axis" (PC 1) accounts for $88 \%$ of the variance with juvenile features to the left (small size, young age, and rapid growth) and adult features to the right (large size, old age, and modest growth). PC 2 explains $9 \%$ of the cumulative variance and is dominated by shear strain, forming a "loading-effect axis."

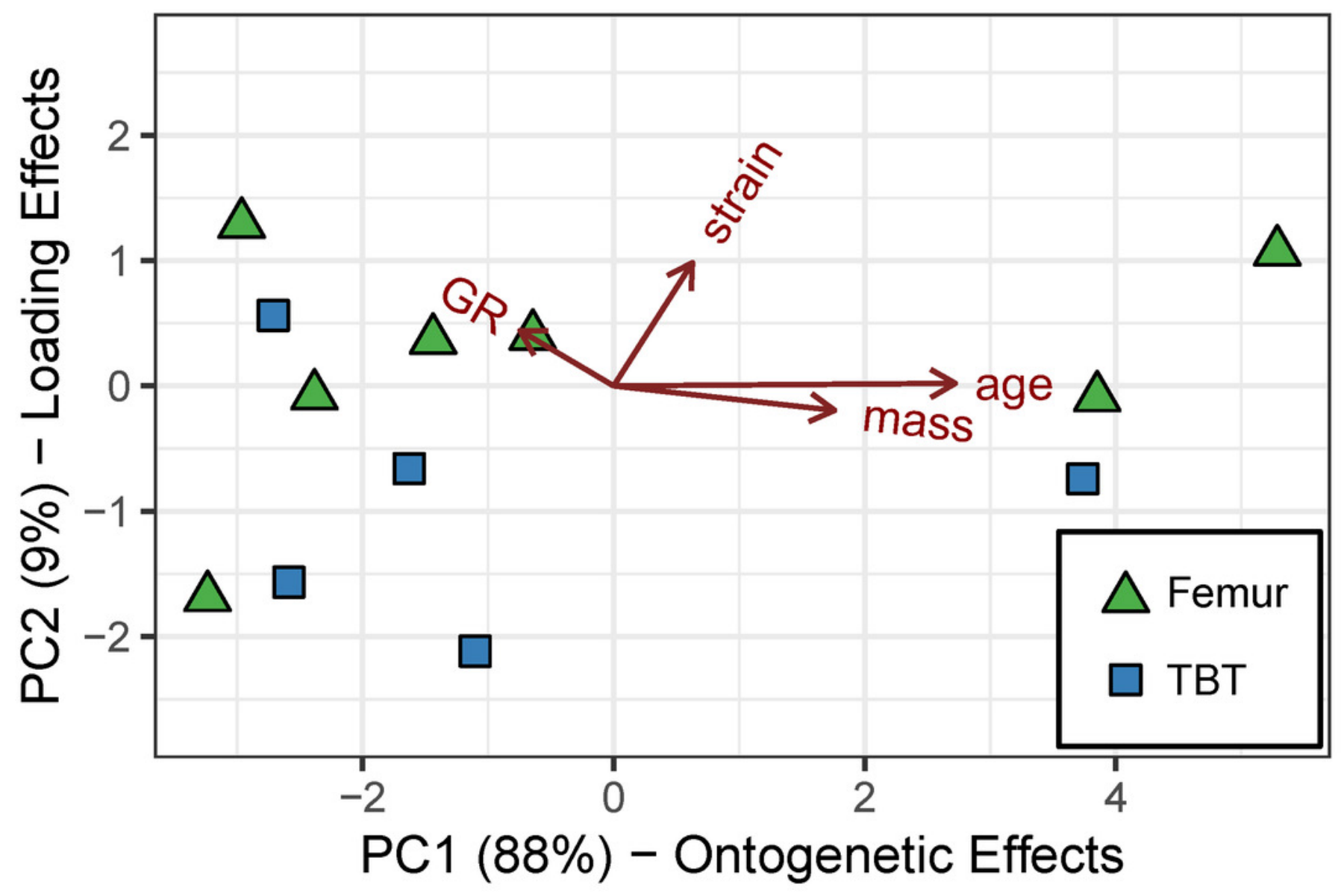




\section{Figure 7}

Effect of the "ontogenetic axis" on laminarity (LI) in the caudal octants of the hindlimb.

Random-intercept beta regression reveals that the "ontogenetic axis" (PC 1) accounts for $78 \%$ of the variation in laminarity from the caudal octants of femur (green triangles) and tibiotarsus (blue squares). Laminarity generally increases along that axis $(p=0.013)$ to which shear strain has a minor contribution. 


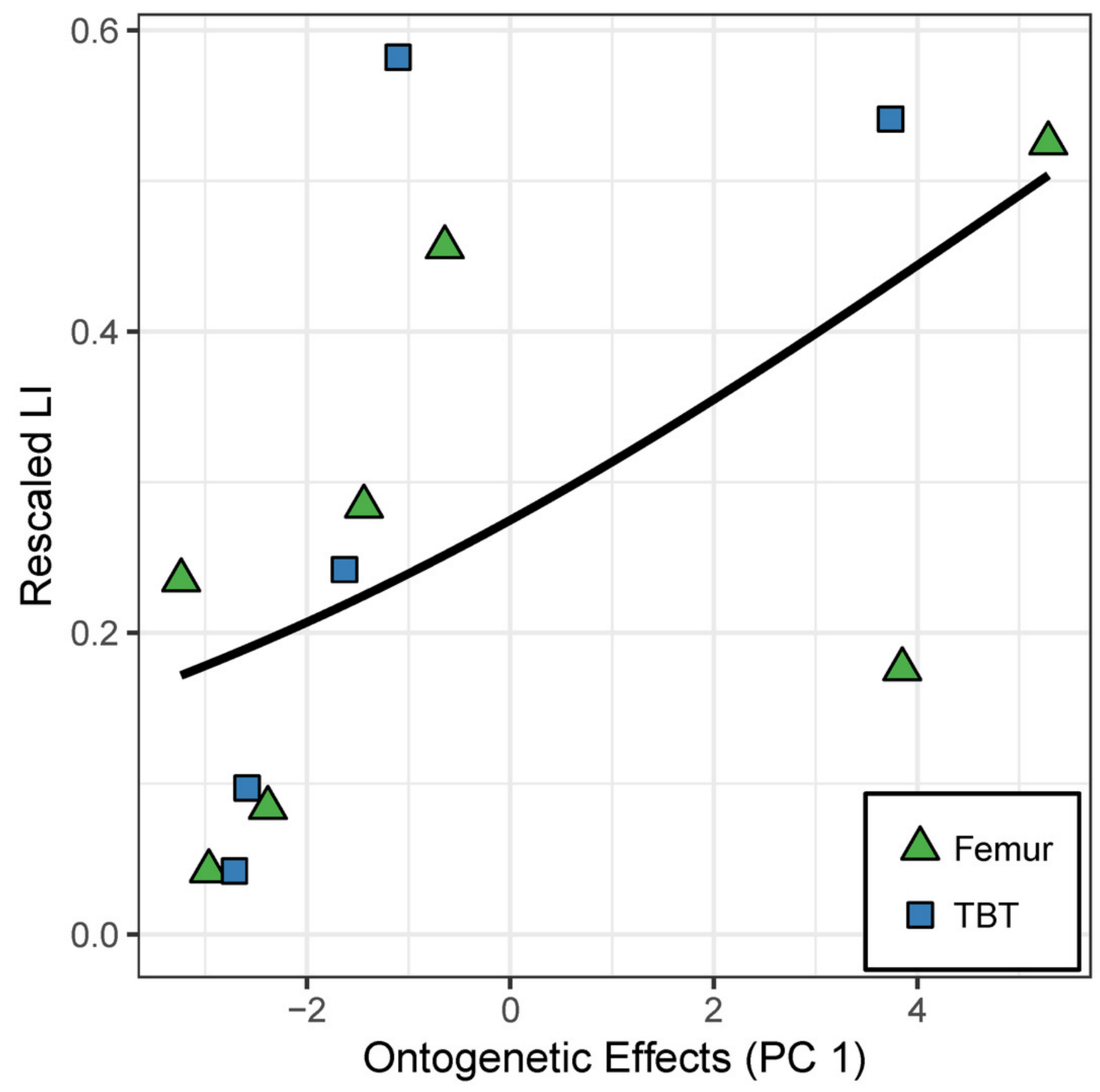




\section{Figure 8}

Robust principal components analysis of the cardinal octants from the humerus, ulna, and radius.

An "ontogenetic axis" (PC 1) accounts for 97\% of the variance with juvenile features to the left (small size, young age, and rapid growth rate) and adult features to the right (large size, old age, and modest growth rate). Residual variation from growth rate largely contributes to an "ontogeny-independent growth rate axis" along PC 2 . This axis only explains $2.3 \%$ of the cumulative variance. 


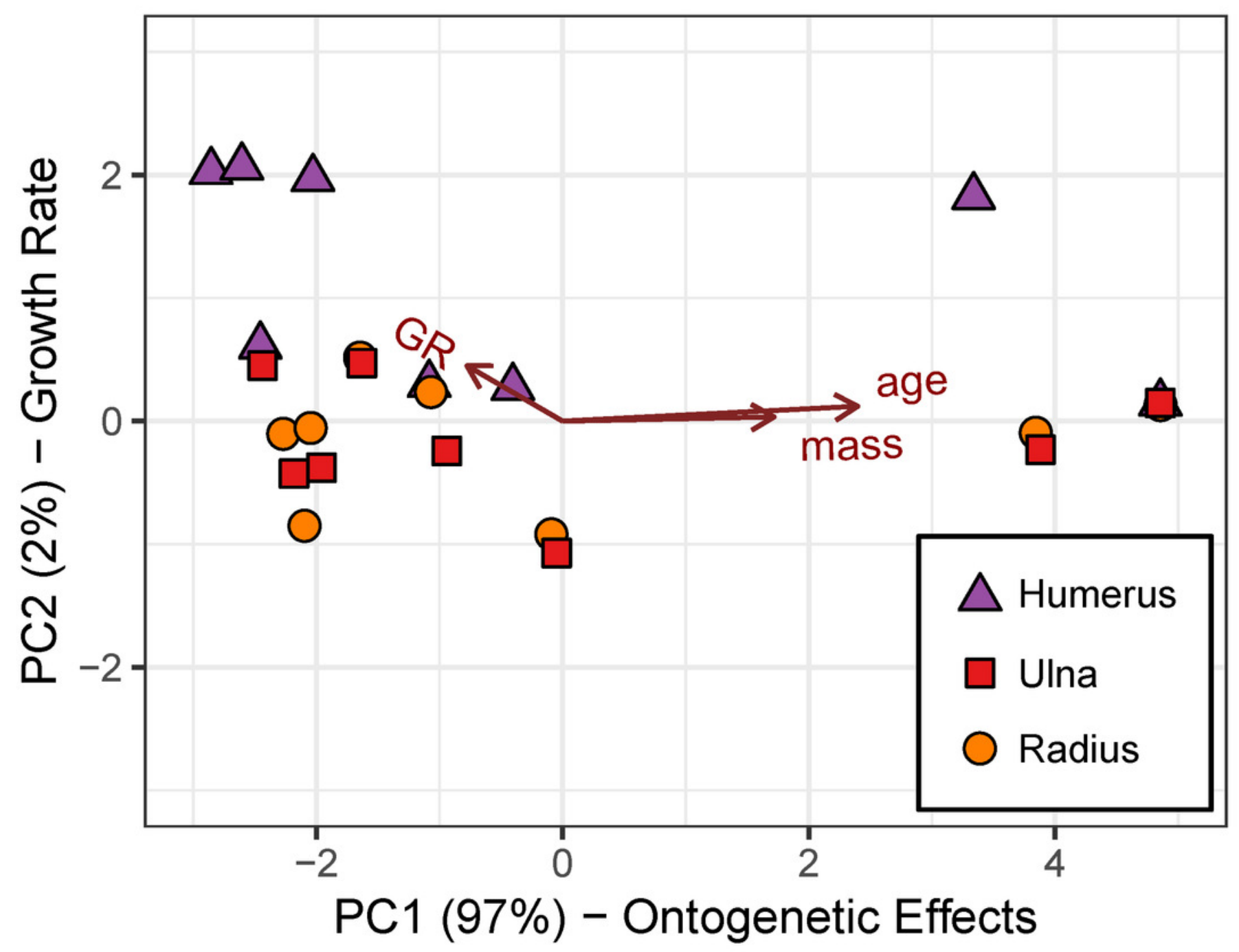


Figure 9

Effect of the "ontogenetic axis" on laminarity (LI) in cardinal octants of the forelimb.

Random-intercept beta regression reveals poor correlation $(p=0.089)$ between laminarity and the "ontogenetic axis" in the humerus (purple triangles), ulna (red squares), and radius (orange circles). 


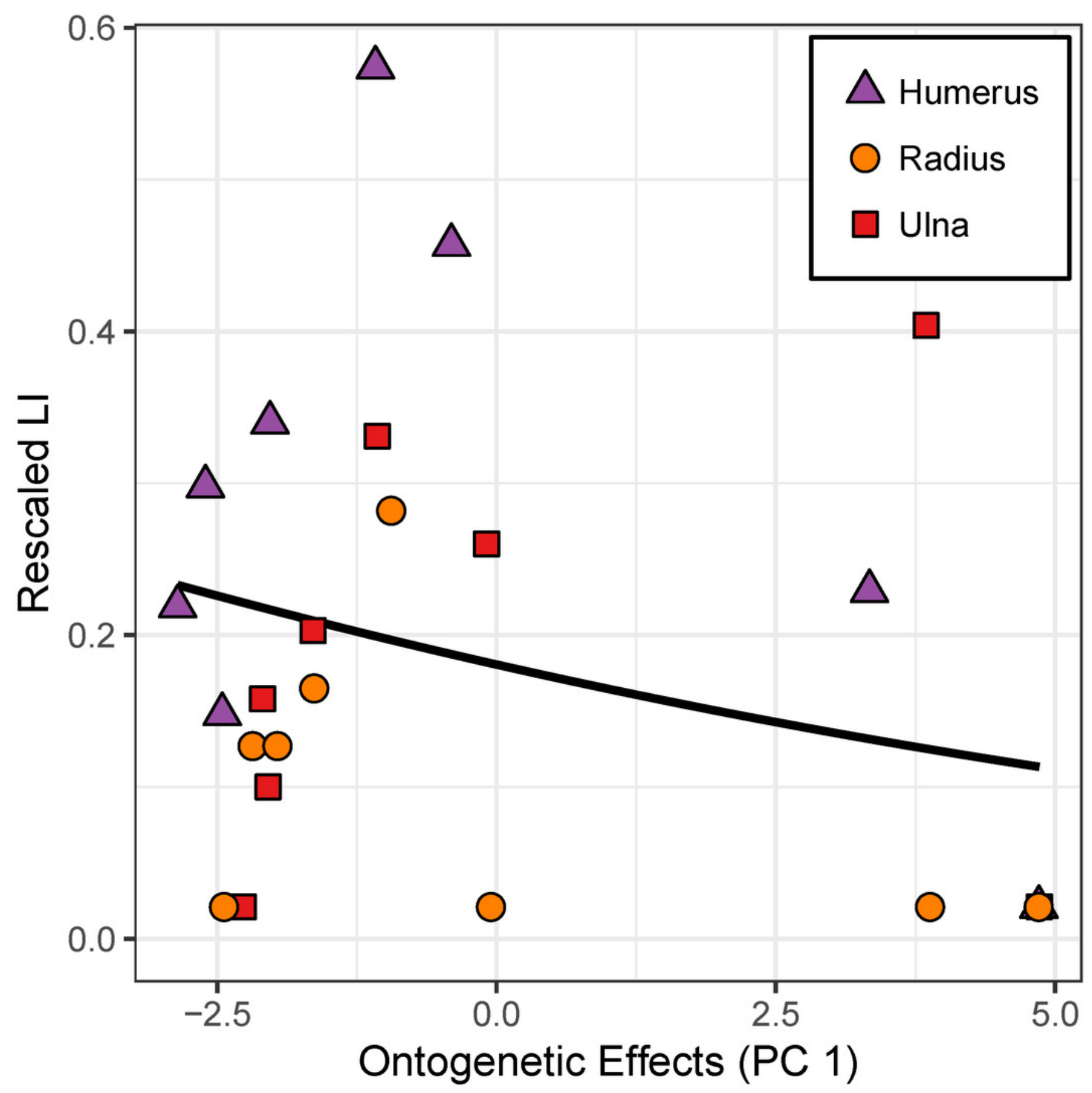




\section{Table 1 (on next page)}

Emu identification number, age at sacrifice, and mass. 
1

\begin{tabular}{|c|c|c|}
\hline Specimen & $\begin{array}{c}\text { Age } \\
\text { (weeks) }\end{array}$ & $\begin{array}{c}\text { Mass } \\
\text { (kg) }\end{array}$ \\
\hline 15 & 2.3 & 0.74 \\
\hline $1 \mathrm{c}$ & 2.4 & 0.94 \\
\hline 17 & 4.6 & 1.53 \\
\hline $14 \mathrm{~b}$ & 8.1 & 4.73 \\
\hline 16 & 12 & 6.85 \\
\hline $2 \mathrm{a}$ & 15.9 & 11.13 \\
\hline 21 & 48 & 28.9 \\
\hline 23 & 60.1 & 29.4 \\
\hline
\end{tabular}

2

3

4 


\section{Table 2 (on next page)}

Growth rate and bone laminarity for emu specimens.

Laminarity Index (LI) was measured in a sample area outlined by the periosteal extent of two bone fluorochromes. Forelimb LI was rescaled following (Smithson \& Verkuilen, 2006) to prepare the data with 0 values for beta regression. 


\begin{tabular}{|c|c|c|c|c|c|}
\hline Specimen & $\begin{array}{c}\text { Age } \\
\text { (weeks) }\end{array}$ & Element & $\begin{array}{c}\text { Growth } \\
\text { Rate } \\
(\mu \mathrm{m} / \mathrm{day})\end{array}$ & $\mathbf{L I}$ & $\begin{array}{c}\text { Rescaled } \\
\text { LI } \\
\text { (Forelimb } \\
\text { only) }\end{array}$ \\
\hline \multirow{5}{*}{15} & \multirow{5}{*}{2.3} & Femur & 130.2 & 0.03 & \\
\hline & & Tibiotarsus & 62.3 & 0.02 & \\
\hline & & Humerus & 25.4 & 0.21 & 0.22 \\
\hline & & Ulna & 6.8 & 0.14 & 0.16 \\
\hline & & Radius & 15.2 & 0 & 0.02 \\
\hline \multirow{5}{*}{$1 \mathrm{c}$} & \multirow{5}{*}{2.4} & Femur & 73.3 & 0.14 & \\
\hline & & Tibiotarsus & 53.8 & 0.12 & \\
\hline & & Humerus & 16.2 & 0.13 & 0.15 \\
\hline & & Ulna & 11.6 & 0 & 0.02 \\
\hline & & Radius & 9.5 & 0.11 & 0.13 \\
\hline \multirow{5}{*}{17} & \multirow{5}{*}{4.6} & Femur & 162.6 & 0.02 & \\
\hline & & Tibiotarsus & 99.1 & 0.01 & \\
\hline & & Humerus & 25.2 & 0.29 & 0.30 \\
\hline & & Ulna & 11.5 & 0.08 & 0.10 \\
\hline & & Radius & 9.4 & 0.11 & 0.13 \\
\hline \multirow{5}{*}{$14 \mathrm{~b}$} & \multirow{5}{*}{8.1} & Femur & 101.1 & 0.14 & \\
\hline & & Tibiotarsus & 68.5 & 0.14 & \\
\hline & & Humerus & 23.8 & 0.33 & 0.34 \\
\hline & & Ulna & 14.4 & 0.19 & 0.20 \\
\hline & & Radius & 14.1 & 0.15 & 0.17 \\
\hline \multirow{5}{*}{16} & \multirow{5}{*}{12} & Femur & 38.3 & 0.48 & \\
\hline & & Tibiotarsus & 41.5 & 0.19 & \\
\hline & & Humerus & 12.2 & 0.58 & 0.57 \\
\hline & & Ulna & 11.8 & 0.32 & 0.33 \\
\hline & & Radius & 8.7 & 0.27 & 0.28 \\
\hline \multirow{5}{*}{$2 a$} & \multirow{5}{*}{15.9} & Femur & 29.4 & 0.56 & \\
\hline & & Tibiotarsus & 29.2 & 0.35 & \\
\hline & & Humerus & 11.1 & 0.45 & 0.46 \\
\hline & & Ulna & 3.4 & 0.25 & 0.26 \\
\hline & & Radius & 2.4 & 0 & 0.02 \\
\hline \multirow{5}{*}{21} & \multirow{5}{*}{48} & Femur & 6.4 & 0.29 & \\
\hline & & Tibiotarsus & 4.9 & 0.39 & \\
\hline & & Humerus & 14.6 & 0.22 & 0.23 \\
\hline & & Ulna & 2.2 & 0.40 & 0.40 \\
\hline & & Radius & 1.3 & 0 & 0.02 \\
\hline 23 & 60.1 & Femur & 5.9 & 0.51 & \\
\hline
\end{tabular}




\begin{tabular}{|l|c|c|c|c|}
\hline \multirow{5}{*}{} & Tibiotarsus & 3.8 & 0.58 & \\
\cline { 3 - 5 } & Humerus & 1.7 & 0 & 0.02 \\
\cline { 2 - 5 } & Ulna & 1.6 & 0 & 0.02 \\
\cline { 2 - 5 } & Radius & 1.7 & 0 & 0.02 \\
\hline
\end{tabular}

1 


\section{Table 3 (on next page)}

Caudal shear strain and caudal octant laminarity for emu specimens.

Caudal shear strain data were previously collected by Main and Biewener (2007). Caudal laminarity index (LI) was measured in a sample area outlined by the periosteal extent of two bone fluorochromes in the caudal octant only. LI values were rescaled following (Smithson \& Verkuilen, 2006) to prepare data with 0 values for beta regression. Only specimens for which caudal shear strain data were available are included. 
1

\begin{tabular}{|c|c|c|c|c|c|}
\hline Specimen & $\begin{array}{c}\text { Age } \\
(\text { weeks) }\end{array}$ & Element & $\begin{array}{c}\text { Caudal Shear } \\
\text { Strain } \\
\text { (microstrain) }\end{array}$ & $\begin{array}{c}\text { Caudal } \\
\text { Octant } \\
\text { LI }\end{array}$ & $\begin{array}{c}\text { Rescaled } \\
\text { Caudal LI }\end{array}$ \\
\hline $1 \mathrm{c}$ & 2.4 & Femur & -308 & 0.21 & 0.24 \\
\hline \multirow[t]{2}{*}{17} & \multirow[t]{2}{*}{4.6} & Femur & -1503 & 0 & 0.04 \\
\hline & & Tibiotarsus & -1397 & 0 & 0.04 \\
\hline \multirow[t]{2}{*}{$14 b$} & \multirow[t]{2}{*}{8.1} & Femur & -997 & 0.05 & 0.08 \\
\hline & & Tibiotarsus & -261 & 0.06 & 0.10 \\
\hline \multirow[t]{2}{*}{16} & \multirow[t]{2}{*}{12} & Femur & -1491 & 0.26 & 0.28 \\
\hline & & Tibiotarsus & -947 & 0.22 & 0.24 \\
\hline \multirow[t]{2}{*}{$2 \mathrm{a}$} & \multirow[t]{2}{*}{15.9} & Femur & -1620 & 0.45 & 0.46 \\
\hline & & Tibiotarsus & -293 & 0.59 & 582 \\
\hline \multirow[t]{2}{*}{21} & \multirow[t]{2}{*}{48} & Femur & -1657 & 0.15 & 0.18 \\
\hline & & Tibiotarsus & -1318 & 0.55 & 0.54 \\
\hline 23 & 60.1 & Femur & -2283 & 0.53 & 0.53 \\
\hline
\end{tabular}

2

3 


\section{Table 4 (on next page)}

Summary of principal components analyses.

Robust principal components analysis summary for (A) cardinal octants from femur and tibiotarsus, (B) caudal octants from femur and tibiotarsus, and (C) cardinal octants from humerus, ulna, and radius. 


\begin{tabular}{|l|c|c|c|c|}
\hline A. Cardinal Octants from Femur and Tibiotarsus \\
\hline & PC 1 & PC 2 & PC 3 & \\
\hline Eigenvalues & 8.182 & 0.403 & 0.037 & \\
\hline Standard deviation & 2.860 & 0.635 & 0.192 & \\
\hline Proportion of variation & 0.949 & 0.047 & 0.004 & \\
\hline Cumulative Proportion & 0.949 & 0.996 & 1.000 & \\
\hline & & & & \\
\hline Mass & 0.560 & 0.021 & 0.828 & \\
\hline Age & 0.769 & 0.357 & -0.529 & \\
\hline Growth rate & -0.307 & 0.934 & 0.184 & \\
\hline & & & & \\
\hline B. Caudal Octants fr.m & & & & \\
\hline
\end{tabular}

\section{B. Caudal Octants from Femur and Tibiotarsus}

\begin{tabular}{|l|c|c|c|c|}
\hline & PC 1 & PC 2 & PC 3 & PC 4 \\
\hline Eigenvalues & 9.435 & 0.989 & 0.233 & 0.032 \\
\hline Standard deviation & 3.072 & 0.994 & 0.482 & 0.179 \\
\hline Proportion of variation & 0.883 & 0.093 & 0.022 & 0.003 \\
\hline Cumulative Proportion & 0.883 & 0.975 & 0.997 & 1.000 \\
\hline & & & & \\
\hline Mass & 0.520 & -0.178 & 0.098 & 0.830 \\
\hline Age & 0.804 & 0.019 & 0.266 & -0.532 \\
\hline Shear strain & 0.185 & 0.898 & -0.381 & 0.122 \\
\hline Growth rate & -0.221 & 0.403 & 0.880 & 0.121 \\
\hline & & & & \\
\hline
\end{tabular}

\section{Cardinal Octants from Humerus, Ulna, and Radius}

\begin{tabular}{|l|c|c|c|c|}
\hline & PC 1 & PC 2 & PC 3 & \\
\hline Eigenvalues & 7.977 & 0.187 & 0.039 & \\
\hline Standard deviation & 2.824 & 0.433 & 0.197 & \\
\hline Proportion of variation & 0.972 & 0.023 & 0.005 & \\
\hline Cumulative Proportion & 0.972 & 0.995 & 1.000 & \\
\hline & & & & \\
\hline Mass & 0.563 & 0.074 & 0.823 & \\
\hline Age & 0.786 & 0.259 & -0.561 & \\
\hline Growth rate & -0.255 & 0.963 & 0.087 & \\
\hline
\end{tabular}




\section{Table 5 (on next page)}

Comparison of random-intercept beta regression models.

Model selection was based on Akaike's Information Criterion $\left(A I C_{c}\right)$ value and $\triangle A I C_{c}$. $(A)$

Cardinal octants from hindlimb, (B) caudal octants from hindlimb, and (C) cardinal octants from forelimb. For each dataset, the best supported model showed the "ontogenetic axis" (PC 1) as the sole predictor of laminarity. 
A. Cardinal Octants from Hindlimb

\begin{tabular}{lcccc}
\hline & \multicolumn{2}{c}{ Model 1 } & \multicolumn{2}{c}{ Model 2 } \\
\cline { 2 - 5 } Variable & $\boldsymbol{\beta}$ & $\mathbf{p}$-value & $\boldsymbol{\beta}$ & $\mathbf{p}$-value \\
\hline Intercept & -1.120 & $1.25 \mathrm{e}-5$ & -1.053 & $3.19 \mathrm{e}-4$ \\
Element(TBT=1) & & & -0.309 & 0.154 \\
PC 1 & 0.337 & $5.51 \mathrm{e}-5$ & 0.348 & $8.92 \mathrm{e}-5$ \\
& & & & \\
Pseudo R & 0.889 & & 0.913 \\
$\mathrm{AIC}_{\mathrm{c}}$ & & 0.5 & & 20.7 \\
$\Delta \mathrm{AIC}_{\mathrm{c}}$ & & 0 & & 20.2 \\
\hline
\end{tabular}

2

3 B. Caudal Octants from Hindlimb

\begin{tabular}{lcccccc}
\hline & \multicolumn{2}{c}{ Model 1 } & \multicolumn{2}{c}{ Model 2 } & \multicolumn{2}{c}{ Model 3 } \\
\cline { 2 - 7 } Variable & $\boldsymbol{\beta}$ & $\mathbf{p}$-value & $\boldsymbol{\beta}$ & $\mathbf{p}$-value & $\boldsymbol{\beta}$ & p-value \\
\hline Intercept & -0.970 & 0.001 & -1.105 & 0.002 & -1.083 & 0.002 \\
PC 1 & 0.186 & 0.013 & & & 0.242 & 0.007 \\
PC 2 & & & -0.200 & 0.169 & -0.356 & 0.056
\end{tabular}

\begin{tabular}{|c|c|c|c|c|c|c|}
\hline \multirow{3}{*}{\multicolumn{2}{|c|}{$\begin{array}{l}\text { Pseudo } \mathrm{R}^{2} \\
\mathrm{AIC}_{\mathrm{c}} \\
\Delta \mathrm{AIC}_{\mathrm{c}}\end{array}$}} & 0.775 & \multicolumn{3}{|c|}{0.841} & 0.828 \\
\hline & & \multirow{2}{*}{$\begin{array}{c}19.1 \\
0 \\
\end{array}$} & \multicolumn{3}{|c|}{51.5} & 41.4 \\
\hline & & & & \multicolumn{2}{|l|}{$\begin{array}{l}31.5 \\
32.4\end{array}$} & 22.3 \\
\hline \multirow[b]{2}{*}{ Variable } & \multicolumn{2}{|c|}{ Model 4} & \multicolumn{2}{|c|}{ Model 5} & \multicolumn{2}{|c|}{ Model 6} \\
\hline & $\beta$ & p-value & $\beta$ & p-value & $\beta$ & p-value \\
\hline Intercept & -1.214 & 0.006 & -1.243 & 0.011 & -1.110 & 0.011 \\
\hline Element $(\mathrm{TBT}=1)$ & 0.508 & 0.118 & 0.432 & 0.224 & 0.092 & 0.782 \\
\hline PC 1 & 0.215 & 0.013 & & & 0.242 & 0.017 \\
\hline PC 2 & & & -0.015 & 0.911 & -0.319 & 0.135 \\
\hline Pseudo $\mathrm{R}^{2}$ & & 0.875 & & 0.882 & & 0.837 \\
\hline $\mathrm{AIC}_{\mathrm{c}}$ & & 91.0 & & 181.6 & & 107.9 \\
\hline$\Delta \mathrm{AIC}_{\mathrm{c}}$ & & 71.9 & & 162.5 & & 88.8 \\
\hline
\end{tabular}

4

5 C. Cardinal Octants from Forelimb

\begin{tabular}{lcccc}
\hline & \multicolumn{2}{c}{ Model 1 } & \multicolumn{2}{c}{ Model 2 } \\
\cline { 2 - 5 } Variable & $\boldsymbol{\beta}$ & $\mathbf{p}-$ value & $\boldsymbol{\beta}$ & $\mathbf{p}$-value \\
\hline Intercept & -1.508 & $1.42 \mathrm{e}-7$ & -0.997 & $7.57 \mathrm{e}-5$ \\
Element(Radius=1) & & & -1.345 & $6.77 \mathrm{e}-4$ \\
Element(Ulna=1) & & & -0.601 & 0.044 \\
PC 1 & -0.112 & 0.089 & -0.117 & 0.030 \\
& & & & \\
Pseudo R & & 0.277 & & 0.704 \\
$\mathrm{AIC}_{\mathrm{c}}$ & & -26.6 & & -20.6 \\
$\Delta \mathrm{AIC}_{\mathrm{c}}$ & & 0 & & 6 \\
\hline
\end{tabular}

